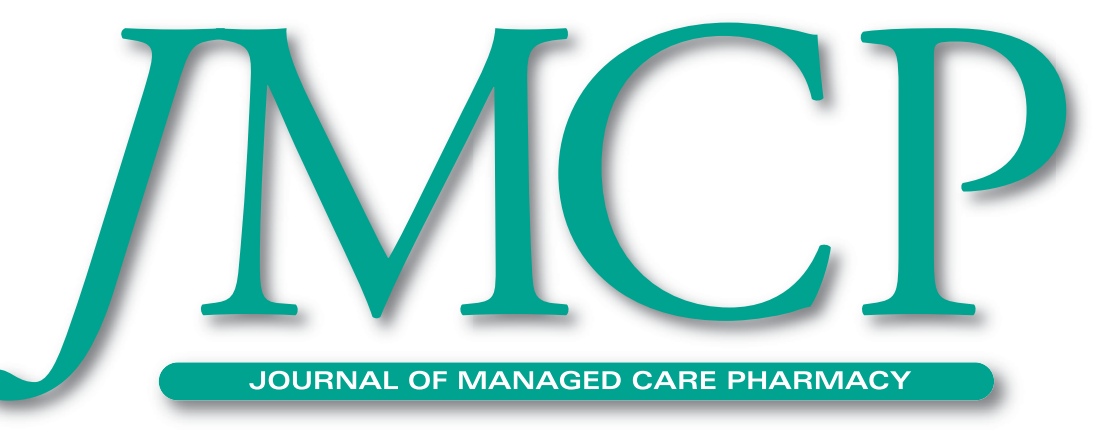

Summary of the Comparative Effectiveness Review on Off-Label Use of Atypical Antipsychotics

Alicia R. Maher, MD

George Theodore, PhD

Supplement

June 2012

Vol. 18, No. 5-b

Continuing Education Activity 


\section{MCP}

Associate Editor

Kathleen A. Fairman, MA

602.867.1343, kfairman@amcp.org

\section{Copy Editor}

Carol Blumentritt, 602.616.7249

cblumentritt@amcp.org

Peer Review Administrator

Jennifer A. Booker, 703.317.0725

jmcpreview@amcp.org

\section{Graphic Designer}

Margie C. Hunter

703.297.9319,mhunter@amcp.org

\section{Account Manager}

Bob Heiman, 856.673.4000

bob.rhmedia@comcast.net

\section{Publisher}

Edith A. Rosato, RPh, IOM

Chief Executive Officer

Academy of Managed Care Pharmacy

This supplement to the Journal of Managed Care Pharmacy (ISSN 1083-4087) is a publication of the Academy of Managed Care Pharmacy, 100 North Pitt St., Suite 400, Alexandria, VA 22314; 703.683.8416; 703.683 .8417 (fax).

Copyright $(\odot)$ 2012, Academy of Managed Care Pharmacy. All rights reserved. No part of this publication may be reproduced or transmitted in any form or by any means, electronic or mechanical, without written permission from the Academy of Managed Care Pharmacy.

POSTMASTER: Send address changes to JMCP, 100 North Pitt St., Suite 400, Alexandria, VA 22314.

\section{Supplement Policy Statement Standards for Supplements to the Journal of Managed Care Pharmacy}

Supplements to the Journal of Managed Care Pharmacy are intended to support medical education and research in areas of clinical practice, health care quality improvement, or efficient administration and delivery of health benefits. The following standards are applied to all JMCP supplements to ensure quality and assist readers in evaluating potential bias and determining alternate explanations for findings and results.

1. Disclose the principal sources of funding in a manner that permits easy recognition by the reader.

2. Disclose the existence of all potential conflicts of interest among supplement contributors, including financial or personal bias.

3. Describe all drugs by generic name unless the use of the brand name is necessary to reduce the opportunity for confusion among readers.

4. Identify any off-label (unapproved) use by drug name and specific off-label indication.

5. Strive to report subjects of current interest to managed care pharmacists and other managed care professionals.

6. Seek and publish content that does not duplicate content in the Journal of Managed Care Pharmacy.

7. Subject all supplements to expert peer review.
Alicia R. Maher, MD, is Assistant Clinical Professor of Psychiatry at the University of California, Los Angeles (UCLA) School of Medicine in Los Angeles, California. She completed medical school at the University of Missouri-Kansas City School of Medicine. She then completed residency in psychiatry at the Harbor-UCLA Medical Center and a fellowship in the interplay of mental and physical health leading to subspecialty board certification in mind-body, or psychosomatic, medicine through UCLA. She is a board certified Diplomate of the American Board of Psychiatry and Neurology. Dr. Maher served as Associate Director of the Psychiatric Consultation Service of Cedars-Sinai Medical Center and Associate Professor of Psychiatry at UCLA. She has particular interest in treating individuals through medical conditions, life transitions, weight management, and attention deficit disorder (ADD and ADHD). In addition to treating patients, Dr. Maher has taught medical students at University of Southern California, University of California, San Francisco, and UCLA. She has trained psychiatry residents at Cedars-Sinai and lectured to professionals and individuals on a wide variety of mental health and wellness topics. She has written several articles for medical journals, and her expertise has been used by Psychiatric Times, Journal of General Internal Medicine, the International Association for Cognitive Behavioral Therapy, and several others. She is also the author of the self-help guide for recognizing and treating ADHD in adults. In addition to her practice at the Akasha Center in Santa Monica, California, Dr. Maher conducts health care research as a Physician Adjunct for the RAND Corporation.

\section{This JMCP supplement was prepared by:}

\section{Alicia R. Maher, MD}

Physician Adjunct

RAND Corporation

Assistant Clinical Professor of Psychiatry

UCLA School of Medicine

Psychiatrist, Mind-Body Medicine Specialist

Akasha Center for Integrative Medicine

520 Arizona Avenue

Santa Monica, CA

Tel.: 310.451.8880; E-mail: Alicia.Ruelaz@cshs.org

George Theodore, PhD

Medical Writer

PRIME Education, Inc., Tamarac, FL

Tel.: 954.718.6055; E-mail: g.theodore@primeinc.org

\section{PRIME CME/CE Reviewers:}

Bradley N. Gaynes, MD, MPH

Professor of Psychiatry

University of North Carolina School of Medicine

Chapel Hill, NC

E-mail: bradley_gaynes@med.unc.edu

\section{David Rudd, PhD, ABPP}

Dean, College of Social \& Behavioral Science,

University of Utah, Scientific Director

National Center for Veterans Studies

University of Utah, Salt Lake City, UT

E-mail: David.rudd@csbs.utah.edu

Scott A. Strassels, PharmD, PhD, BCPS

Assistant Professor of Public Health

The University of Texas at Austin College of Pharmacy

Division of Pharmacy Practice, Austin, TX

E-mail: scotts1@mail.utexas.edu

Kathleen R. Roose, RN

Nurse Case Manager

Skyline Ltd., Raleigh, NC

E-mail: Kathleen.r.Roose.ctr@us.army.mil

\section{JMCP Peer Reviewers:}

Sara C. Erickson, PharmD

Sr. Outcomes Researcher

OptumRx, Irvine, CA

E-mail: sara.c.erickson@optum.com

Patrick R. Finley, PharmD, BCPP

Professor of Clinical Pharmacy (Psychopharmacology \& Behavioral Health)

University of California at San Francisco School of Pharmacy

San Francisco, CA

E-mail: finleyp@pharmacy.ucsf.edu

Bridget M. Flavin, PharmD

RegenceRx, Portland, OR

E-mail: Bridget.Flavin@regence.com

Jessica L. Gören, PharmD, BCPP

Associate Professor, University of Rhode Island

Clinical Psychiatric Pharmacist, Cambridge Health Alliance

Instructor in Psychiatry, Harvard University

Cambridge, MA

E-mail: jgoren@challiance.org

Jane Nelson Bolin, RN, JD, PhD

Interim Department Chair, Associate Professor, Director

Southwest Rural Health Research Center, Texas A\&M Health Science Center

School of Rural Public Health, Dept. of Health Policy \& Management

College Station, TX

E-mail: JBolin@srph.tamhsc.edu 


\section{Table of Contents}

\section{Summary of the Comparative Effectiveness Review on Off-Label Use of Atypical Antipsychotics}

Alicia R. Maher, MD, and George Theodore, PhD

\section{S3 Abstract}

S5 Systematic Review Methods

S6 Key Question 1: Utilization of Atypical Antipsychotics

S7 Key Question 2: Efficacy and Comparative Effectiveness of Atypical Antipsychotics

S10 Key Question 3: Efficacy and Harms with Off-Label Use in Subpopulations and Severity and Subtype of Condition

S10 Key Question 4: Comparison of Adverse Effects of Off-Label Use of Atypical Antipsychotics Within the Class and Other Drugs

S13 Key Question 5: Dosing and Treatment Duration for Off-Label Indications

S13 Study Limitations and Directions for Future Research

S13 Conclusions

S15 Commentary

S16 References

\section{Target Audiences}

This CME activity is designed to meet the educational needs of physicians, psychologists, pharmacists, nurses, and case managers.

\section{Learning Objectives}

Based on the findings from AHRQ's comparative effectiveness review of research of off-label use of atypical antipsychotics:

1. Summarize the trends and novel uses of off-label applications of atypical antipsychotics

2. Assess the comparative benefits and harms of off-label applications of atypical antipsychotics on patient subpopulations

3. Discuss the efficacy and comparative effectiveness of atypical antipsychotics for off-label indications

\section{Funding}

There is no fee for this CME/CE activity. This learning activity is sponsored by PRIME Education, Inc. (PRIME) and was prepared and funded under contract HHSA290201000006G from the Agency for Healthcare Research and Quality (AHRQ), U.S. Department of Health and Human Services (HHS). PRIME Education, Inc. is an accredited provider of continuing medical education that receives independent educational grants from various pharmaceutical manufacturers.

\section{Continuing Education Title}

Summary of the Comparative Effectiveness Review on Off-Label Use of Atypical Antipsychotics

Release date: June 30, 2012

Expiration date: September 30, 2013 


\section{Physician Credit Designation Statement}

PRIME Education, Inc. (PRIME®) is accredited by the Accreditation Council for Continuing Medical Education to provide continuing medical education for physicians. PRIME designates this enduring material for a maximum of 1.5 AMA PRA Category 1 Credit $^{\mathrm{TM}}$. Physicians should claim only the credit commensurate with the extent of their participation in the activity.

\section{Psychologist Accreditation Statement}

PRIME Education, Inc. (PRIME®) is approved by the American Psychological Association to sponsor continuing education for psychologists. PRIME® maintains responsibility for this program and its content.

\section{Pharmacist Accreditation Statement}

C. This curriculum has been approved for 1.5 contact hours by PRIME. PRIME is accredited by the Accreditation 1E. Council for Pharmacy Education as a provider of continuing pharmacy education.

The universal activity number for this activity is 0255-0000-12-025-H01-P.

This learning activity is Knowledge-based.

\section{Nurse Accreditation Statement}

PRIME Education, Inc. is accredited as a provider of continuing nursing education by the American Nurses Credentialing Center's Commission on Accreditation.

PRIME Education, Inc. designates this activity for 1.5 contact hours.

\section{Case Manager Accreditation Statement}

The Commission for Case Manager Certification designates this educational activity for 1.0 contact hour for certified case managers.

\section{Credit Instructions:}

Continuing Education for this program is processed through AHRQ at www.ce.effectivehealthcare.ahrq.gov.

In order to receive $C E$ credit for this program, you must complete the following:

1. Review the activity in its entirety.

2. Complete an online posttest at http://ce.effectivehealthcare.ahrq.gov Code: CER36. To receive credit, you must earn a score of $100 \%$. You will have 2 opportunities to pass the posttest.

3. Complete an online program evaluation form.

Upon successful completion, you will automatically receive your CME/CE statement. Your CME/CE credits will be automatically archived and tracked for you at www.primeinc.org. Information is kept confidential. There is no fee for this learning activity.

\section{DISCLOSURES}

Alicia R. Maher received compensation from PRIME Education, Inc. for work performed in creating this supplement. George Theodore is an employee of PRIME Education, Inc., a medical education company that receives grants and funding for educational programs from various pharmaceutical manufacturers. Theodore analyzed the source document, wrote this summary, and revised this summary with the assistance of Maher.

Bradley N. Gaynes, M. David Rudd, Scott A. Strassels, and Kathleen R. Roose report no financial interest or other relationships with companies with commercial interests in atypical antipsychotic therapy or other potential conflicts of interest related to the subjects in this report. Gaynes, Strassels, and Roose were compensated by PRIME to review the manuscript. Karen Gunning received compensation from PRIME Education, Inc. for writing the commentary and reports no consulting relationships related to the subject of this report. Bridget Flavin, Sara Erickson, Patrick Finley, and Jane Nelson Bolin report no financial interests or other relationships with companies with commercial interests in treatment with atypical antipsychotics or other potential conflicts of interest related to the subjects in this report.

\section{DISCLOSURE OF OFF-LABEL USE}

This report describes uses of atypical antipsychotics (aripiprazole, olanzapine, quetiapine, risperidone, and ziprasidone) that are not approved by the U.S. Food and Drug Administration.

\section{ACKNOWLEDGEMENTS}

This summary article is based on a comparative effectiveness review conducted by investigators at the Southern California Evidence-based Practice Center (EPC). For contributing the clinical commentary included in this JMCP supplement, the authors thank Karen Gunning of the University of Utah Department of Pharmacotherapy.

This learning activity was prepared and funded under contract HHSA290201000006G from the Agency for Healthcare Research and Quality (AHRQ), U.S. Department of Health and Human Services (HHS). The activity is intended to inform health professionals about AHRQ's comparative effectiveness research findings and to identify methods for incorporating the findings into practice. The content in this article is based on the evidence that was available at the time the AHRQ Comparative Effectiveness Review of "Off-Label Use of Atypical Antipsychotics: An Update" was published (September 2011, AHRQ Publication No. 11-EHC087-EF). The full report is available at: http:// effectivehealthcare.ahrq.gov/ehc/products/150/778/CER43_Off-LabelAntipsychotics_20110928.pdf. 


\title{
Summary of the Comparative Effectiveness Review on Off-Label Use of Atypical Antipsychotics
}

\author{
Alicia R. Maher, MD, and George Theodore, PhD
}

\begin{abstract}
BACKGROUND: Conventional and atypical antipsychotic medications are approved by the FDA for treatment of schizophrenia and bipolar disorder. Over many decades, the widespread use of conventional antipsychotics produced various side effects requiring additional medications, such as the atypical antipsychotics. Beginning in 2006, 9 atypical antipsychotic drugs have been approved by the FDA for indications that were previously off-label uses: aripiprazole (as augmentation for major depressive disorder [MDD] and for autism spectrum disorders ), asenapine, clozapine, iloperidone, olanzapine (in combination with fluoxetine for MDD and bipoIar depression), paliperidone, quetiapine (quetiapine and quetiapine XR [extended release] as monotherapy in bipolar depression and quetiapine XR as augmentation for MDD), risperidone (for autism spectrum disorders), and ziprasidone. In 2006, the Agency for Healthcare Research and Quality (AHRQ) published a systematic review on the comparative effectiveness of off-label uses of atypical antipsychotics. Since that time, numerous studies have been published evaluating these therapies in various new off-label uses; new or increased adverse effects have been observed with off-label uses; new atypical antipsychotics have been approved; and previously offlabel uses have been approved for some atypical antipsychotics. Hence, AHRQ published an updated review in September 2011 that summarized the benefits and harms of atypical antipsychotics in the treatment of attentiondeficit hyperactivity disorder/attention deficit disorder (ADHD), anxiety, behavioral disturbances of dementia and severe geriatric agitation, depression, eating disorders, insomnia, obsessive-compulsive disorder (OCD), personality disorder, post-traumatic stress disorder (PTSD), substance use and dependence disorders, and Tourette's syndrome. The new report also investigated topics for which data in the previous report were found to be insufficient to make conclusions, including subpopulations (i.e., race/ethnicity, gender) that would benefit most from atypical antipsychotics, appropriate dose, and time needed to see clinical improvement. The 2011 review included the following atypical antipsychotics: aripiprazole, olanzapine, quetiapine, risperidone, and ziprasidone; no clinical trials were found for off-label use of the 3 most recently FDA-approved atypical antipsychotics (asenapine, iloperidone, and paliperidone).
\end{abstract}

OBJECTIVES: To (a) familiarize health care professionals with the methods and findings from AHRQ's 2011 Comparative Effectiveness Review (CER) of off-label use of atypical antipsychotics, (b) encourage consideration of the clinical and managed care applications of the review findings, and (c) identify limitations and gaps in the existing research with respect to the benefits and risks of off-label use of atypical antipsychotics.

SUMMARY: Antipsychotic medications are FDA approved for the treatment of schizophrenia and bipolar disorder. Conventional antipsychotics have been widely used for decades and spurred the development of the atypical antipsychotics. Atypical antipsychotics were produced and are now being used for patients who may have experienced various side effects while using conventional antipsychotics.

In 2006, an AHRQ study reviewed off-label uses of atypical antipsychotics (excluding clozapine because of its association with potentially fatal bone marrow suppression and the requirement for frequent blood tests for safety monitoring). Findings indicated that the most common off-label uses of these drugs included depression, OCD, PTSD, personality disorders, Tourette's syndrome, autism, and agitation in dementia. The reviewers concluded in $\mathbf{2 0 0 6}$ that overall there was not sufficiently high strength of evidence of efficacy for any off-label use of atypical antipsychotics. There was, however, strong evidence for an increased risk of adverse events with off-label use, including significant weight gain and sedation and increased mortality among the elderly.
Since the 2006 review, significant developments occurred in the use of atypical antipsychotics, including FDA approval of the atypical antipsychotics asenapine, iloperidone, and paliperidone and FDA approval of previous off-label uses: (a) quetiapine and quetiapine XR as monotherapy in bipolar depression; (b) quetiapine XR as augmentation therapy for MDD; (c) aripiprazole as augmentation therapy for MDD; (d) olanzapine/fluoxetine combination for MDD; (e) olanzapine/fluoxetine combination for bipolar depression; and (f) risperidone and aripiprazole for autism spectrum disorders. Additional studies have been published for new off-label uses, and there have been reports of new or increased adverse effects for off-label uses.

Further review of previously insufficient information was warranted on subpopulations where treatment modification such as dosing may increase efficacy. The 2006 review did not have sufficient information to make conclusions regarding subpopulations (i.e., race/ethnicity, gender) that would benefit most from atypical antipsychotics, appropriate dosing, and the duration of treatment needed to see clinical improvement.

The updated AHRQ report in 2011 reviewed off-label uses of atypical antipsychotic medications in anxiety, ADHD, behavioral disturbances of dementia and severe geriatric agitation, MDD, eating disorders, insomnia, OCD, PTSD, personality disorders, substance abuse, and Tourette's syndrome; autism was included in the 2006 review but is now reviewed in a separate report of the comparative effectiveness of antipsychotics for onlabel uses. The significant findings in the updated review include (a) small but statistically significant benefits for olanzapine, aripiprazole, and risperidone for elderly patients with dementia; (b) quetiapine appears superior to placebo for general anxiety disorder (GAD); (c) risperidone was associated with benefits in the treatment of OCD; and (d) adverse events are common. Atypical antipsychotics were not effective in the treatment of eating disorders or personality disorder. The evidence did not support the use of atypical antipsychotics in the treatment of substance abuse, and data were inconclusive for the use of these medications for insomnia. The number needed to harm (NNH) was calculated for adverse events in elderly patients, including risk of death ( $\mathrm{NNH}=87$ ), stroke ( $\mathrm{NNH}=53$ for risperidone), extrapyramidal symptoms ( $\mathrm{NNH}=10$ for olanzapine and $\mathrm{NNH}=20$ for risperidone), and urinary symptoms ( $\mathrm{NNH}=16$ to 36 ). Adverse events in nonelderly adults included weight gain (particularly with olanzapine), fatigue, sedation, akathisia (with aripiprazole), and extrapyramidal symptoms.

J Manag Care Pharm. 2012;18(5-b):S3-S20

Copyright $\odot 2012$, Academy of Managed Care Pharmacy. All rights reserved.

A ntipsychotic medications are approved by the U.S. Food and Drug Administration (FDA) for the treatment of schizophrenia and bipolar disorder (Table 1). In 2006, the Agency for Healthcare Research and Quality (AHRQ) published a systematic review on the comparative effectiveness of off-label uses of atypical antipsychotics. Beginning in 2006, 9 atypical antipsychotic drugs have been approved by the FDA for indications that were previously off-label uses: aripiprazole (as augmentation for major depressive disorder [MDD] and for autism spectrum disorders ), asenapine, clozapine, iloperidone, olanzapine (in combination with fluoxetine for MDD and bipolar depression), paliperidone, quetiapine (quetiapine and quetiapine XR [extended release] as monotherapy in bipolar 


\begin{tabular}{|c|c|}
\hline Drug & Date of Original FDA Approvala \\
\hline Clozapine $^{\mathrm{b}}$ & September 26,1989 \\
\hline Risperidone & December 29,1993 \\
\hline Olanzapine & September 30,1996 \\
\hline Quetiapine & September 27,1997 \\
\hline Ziprasidone & February 5, 2001 \\
\hline Aripiprazole & November 15, 2002 \\
\hline Paliperidone $^{\mathrm{c}}$ & December 19, 2006 \\
\hline Iloperidone ${ }^{\mathrm{c}}$ & May 6, 2009 \\
\hline Asenapinec & August 13, 2009 \\
\hline \multicolumn{2}{|c|}{$\begin{array}{l}\text { aDerived from FDA information at http://www.accessdata.fda.gov. } \\
b \text { Excluded from this comparative effectiveness review. } \\
\text { cNo evidence of off-label use was discovered for these drugs. } \\
\text { FDA =U.S. Food and Drug Administration. }\end{array}$} \\
\hline
\end{tabular}

depression and quetiapine XR as augmentation for MDD), risperidone (for autism spectrum disorders), and ziprasidone (Table 2).

This supplement summarizes the key findings from the AHRQ 2011 Comparative Effectiveness Review (CER), ${ }^{1}$ which describes the efficacy and harms of off-label use of atypical antipsychotics, updated from the 2006 AHRQ CER report. ${ }^{2}$ Scientific literature on the utilization, efficacy, adverse effects, dosing, and treatment duration on patient outcomes is reviewed in order to inform prescribing decisions. Applications of the AHRQ findings to practice are discussed to provide clinicians information to support evidence-based care for their patients.

\section{Off-Label Use of Antipsychotics}

Anxiety. Each year, approximately 40 million Americans aged 18 years or older suffer from excessive anxiety, defined as irrational dread of common, everyday situations. ${ }^{3,4}$ This disabling disorder can be treated with medication (e.g., antidepressants), psychotherapy, or both. ${ }^{5}$ Anxiety disorders are characterized by abnormal or pathological fear and anxiety and include acute stress disorder, agoraphobia (with or without a history of panic disorder), generalized anxiety disorder (GAD), and panic disorder (with or without agoraphobia). ${ }^{5}$ Although obsessivecompulsive disorder (OCD) and post-traumatic stress disorder (PTSD) are also anxiety disorders, for the purposes of the CER update they were covered separately. Among these disorders, the one most commonly treated with atypical antipsychotics is GAD, which affects 6.8 million American adults. A diagnosis of GAD requires at least 6 months of persistent and excessive anxiety and worry that may lead to insomnia, difficulty concentrating, and social and occupational impairment. ${ }^{4}$

ADHD. Attention-deficit hyperactivity disorder (ADHD) and its subtypes are characterized by hyperactivity, inattention, and impulsive behavior. ${ }^{1}$ ADHD is the most common disorder

\section{TABLE 2 Therapeutic Indications of Atypical Antipsychotics Recently Approved by the FDA}

\begin{tabular}{|c|c|c|}
\hline Therapy & Approved (On-Label) Use & $\begin{array}{c}\text { Date of } \\
\text { Approved Use }\end{array}$ \\
\hline Aripiprazole & Augmentation for MDD & September 20, 2006 \\
\hline Aripiprazole & Autism spectrum disorders & November 20, 2007 \\
\hline $\begin{array}{l}\text { Olanzapine/ } \\
\text { fluoxetine }\end{array}$ & Combination for MDD & July 17, 2007 \\
\hline $\begin{array}{l}\text { Olanzapine/ } \\
\text { fluoxetine }\end{array}$ & Combination for bipolar depression & July 17, 2007 \\
\hline Quetiapine & Monotherapy in bipolar depression & October 23, 2006 \\
\hline Quetiapine ER & Monotherapy in bipolar depression & May 17, 2007 \\
\hline Quetiapine ER & Augmentation for MDD & May 17, 2007 \\
\hline Risperidone & Autism spectrum disorders & October 6, 2006 \\
\hline
\end{tabular}

a Derived from FDA information at http://www.accessdata.fda.gov

$E R=$ extended release; FDA =U.S. Food and Drug Administration; $M D D=$ major depressive disorder.

diagnosed in school-age children but may persist into adulthood. Diagnosis requires having 6 or more symptoms persisting for more than 6 months, leading to impairments in 2 settings, such as home and work. Symptoms must be exhibited prior to 7 years of age and must be considered maladaptive., ${ }^{1,4}$ Evaluations for ADHD are done in relation to the patient's developmental level, and symptoms must not be attributable to other conditions or pathologies. Psychotherapy, pharmacotherapy, and educational interventions are used alone or in combination to improve outcomes in ADHD.

Dementia. Deficits in more than 1 domain of cognitive function (memory, language production and understanding, naming and recognition, skilled motor activity, and planning and executive functioning) define dementia. ${ }^{1,6}$ The 2 most common forms of dementia, Alzheimer's and vascular dementia, have distinct causes, although they commonly co-occur. Psychotic symptoms are frequent, and behavioral disturbances often lead to placement in a nursing home. Management of dementia may include behavioral and psychopharmacologic interventions, such as acetylcholinesterase inhibitors or antipsychotics. ${ }^{6}$

Depression. Depression is a symptom cluster that may include low mood; inability to experience pleasure; disturbances in sleep and appetite; loss of energy; difficulty concentrating; feelings of guilt, worthlessness, and hopelessness; and suicidal thoughts. ${ }^{7}$ Depressive symptoms are seen in a variety of disorders, including unipolar depression, bipolar depression, major depression with or without psychotic features, and depression occurring with psychotic disorders (e.g., schizophrenia or schizoaffective disorder). ${ }^{8}$ Current pharmacologic treatment guidelines for major depression are expressed algorithmically. Intolerable side effects or lack of improvement following an adequate trial are potential reasons for treatment failure. ${ }^{9}$ 
Common pharmacotherapy includes serotonin-enhancing antidepressants, antidepressants with dual reuptake inhibition (serotonin and norepinephrine), and augmenting agents, including the atypical antipsychotics. ${ }^{1,2}$ A combination of antidepressant and atypical antipsychotic is often used in cases that include psychotic features. ${ }^{9,10}$

Eating Disorders. Eating disorders include anorexia nervosa and bulimia nervosa, the causes of which are poorly understood. ${ }^{1,8}$ Eating disorders usually begin in late adolescence or early adulthood and affect men as well as women, although they are more common in women. ${ }^{11}$ Medications, nutritional counseling, and psychotherapy are commonly used to treat eating disorders.

Insomnia. Insomnia is characterized by persistent difficulty falling asleep and/or difficulty staying asleep. ${ }^{8}$ The term "insomnia" was used in the CER update to cover all 4 types of sleep disorders (primary sleep disorders, sleep disorder related to another mental disorder, sleep disorder due to a general medical condition, and substance-induced sleep disorder). Medications, pain, hormonal shifts, and mental and other medical disorders may all cause insomnia, ${ }^{12}$ making this a multifaceted disorder. Criteria for a diagnosis of primary insomnia include various types of temporal sleep disturbances that must cause significant distress or functional impairment, must not occur during the course of another mental or medical disorder, and must not be due to the physiological effects of a substance (e.g., alcohol, medication). ${ }^{1,8}$

Obsessive-Compulsive Disorder. OCD is characterized by (a) repetitive, intrusive, unwanted thoughts, impulses, or images and (b) compensatory compulsive behaviors that reduce or remove the distress caused by the obsessions. ${ }^{13}$ Psychiatric morbidity results from distress and the time devoted to compulsions, as well as compulsion-induced dysfunction. Standard treatments include psychopharmacologic approaches using serotonin reuptake inhibitors, such as fluoxetine, and cognitive-behavioral therapy, which promotes a kind of learning through exposure to the feared or unpleasant stimulus and prevention of the compulsive response..$^{1,13}$ Limited response to both treatments is common, and various psychopharmacologic agents, including the atypical antipsychotics, have been tested for their abilities to augment serotonin reuptake inhibitors.

Post-Traumatic Stress Disorder. Following exposure to trauma such as war or rape, patients may experience PTSD and manifest debilitating symptoms that may be categorized as reexperiencing, avoidance and numbing, and increased arousal. ${ }^{14}$ Patients with PTSD may have symptomatic mood, anxiety, and psychotic effects that may respond to atypical antipsychotics. Cognitive-behavioral and other psychotherapies are also implemented in the treatment of PTSD symptoms. ${ }^{14}$
Personality Disorders. The Diagnostic and Statistical Manual of Mental Disorders (DSM-IV-TR) ${ }^{8}$ defines 10 personality disorders. These have in common an onset in adolescence or early adulthood, stability over time, and progression to distress or impairment. ${ }^{8}$ Because of the nature of these disorders, they are primarily treated with psychotherapy to facilitate longterm personality change, although medications may play a role in moderating some of the symptomatic manifestations. Schizotypal personality disorder (SPD) and borderline personality disorder (BPD) were the only 2 personality disorders treated with atypicals in clinical trials. ${ }^{1}$ Patients with SPD undergo behavioral and perceptual changes that are often similar to mild schizophrenia, which is the rationale for using atypical antipsychotics in this condition. Similarly, atypical antipsychotics have been used in BPD due to the occurrence of psychotic symptoms and mood disturbance.

Substance Abuse. The CER update covered substance abuse and dependence on substances including alcohol, cocaine, marijuana, heroin, ecstasy, methamphetamine, and opioids. Caffeine and nicotine dependence were excluded. Substance abuse is a pattern of substance use leading to many adverse results from continual use. ${ }^{8}$ Diagnosis of dependence is based upon continual substance use despite significant problems related to the substance. ${ }^{8}$

Tourette's Syndrome. Tourette's syndrome is characterized by multiple, rapid, recurrent, stereotyped motor movements and vocal tics. Diagnosis requires that tics occur by 18 years of age, but usually patients experience tics around 6 years of age. Pharmacologic treatments include antipsychotic medications, clonidine, benzodiazepines, and some tricyclic antidepressants. $^{1}$

\section{Systematic Review Methods}

This section summarizes the methods by which the CER was conducted. Complete details about the methods are provided in the full technical report published by AHRQ. ${ }^{1}$

\section{Key Questions and Comparisons}

The investigators attempted to answer the following 5 key clinical questions:

Key Question 1. What are the leading off-label uses of atypical antipsychotics in utilization studies? How have trends in utilization changed in recent years, including inpatient versus outpatient use? What new uses are being studied in trials?

Key Question 2. What does the evidence show regarding the efficacy and comparative effectiveness of atypical antipsychotics for off-label indications?

Sub-Key Question 2. How do atypical antipsychotic medications compare with other drugs, including conventional antipsychotics, for treating off-label indications? 
Key Question 3. What subset of the population would potentially benefit from off-label uses? Do efficacy, effectiveness, and harms differ by race/ethnicity, gender, and age group? By severity of condition and clinical subtype?

Key Question 4. What are the potential adverse effects and/ or complications involved with off-label prescribing of atypical antipsychotics? How do they compare within the class and with other drugs used for the conditions?

Key Question 5. What are the effective dose and time limit for off-label indications?

\section{Literature Search and Study Selection}

Studies included in the CER update were identified through comprehensive searches of published biomedical literature using the following: PubMed (which includes MEDLINE), EMBASE, PsychINFO, DARE, CINAHL, the Cochrane Central Register of Controlled Trials, the Cochrane Database of Systematic Reviews, and ClinicalTrials.gov. Searches of these databases were conducted by the reviewers and staff at the Evidence-based Practice Center (EPC) for the period from June 1, 2008, through May 2011 for aripiprazole, olanzapine, quetiapine, risperidone, and ziprasidone. The search for off-label use of the newly approved atypicals (iloperidone, paliperidone, and asenapine) included all years available in the electronic databases through May 2011. The EPC also searched for relevant trials in the National Institutes of Health (NIH) Clinical Trials database, the FDA and Health Canada databases, references of included studies, references of relevant reviews, personal files from related topic projects, and unpublished studies requested from pharmaceutical manufacturers. Two investigators reviewed the studies against a screening form that collected data on medication, psychiatric condition, study design, population, sample size, and study duration. Existing systematic reviews; randomized controlled trials; nonrandomized clinical trials; and large observational studies, where appropriate, were included in the review. Studies that did not report any outcomes of efficacy, effectiveness, safety/adverse events, or utilization patterns were excluded. The reviewers did not limit inclusion by study duration. Clinical trials were used to review efficacy outcomes, and observational studies were used when no clinical trials were found for a given condition or drug of interest. All reported side effects and adverse events were abstracted from clinical trials, even if the trial did not report efficacy or effectiveness results. Large observational studies of adverse events were included, as were reports of utilization and prescribing patterns if they discussed use since 1995. The updated review used the National Library of Medicine's Medical Subject Headings (MeSH) key word nomenclature with the same basic search rules used for the original report. New terms and generic names were added for the additional pharmacotherapies covered in the update.

\section{Evaluations of Study Quality and Rating the Strength of the Body of Evidence}

EPC investigators independently assessed the quality of each included study based on the Jadad scale, which scores randomization, blinding, and description of withdrawals and dropouts. ${ }^{1,15,16}$ Investigators assessed quality of observational studies using the Newcastle-Ottawa Scale, which evaluates selection, comparability (of cohorts), and outcomes. ${ }^{1}$

Overall study quality was assessed as good, fair, or poor based on the risk for bias. Studies rated as good had the least bias, with formal randomized designs and results that were considered valid and devoid of reporting errors. Fair studies were susceptible to some bias and had missing information, while poor studies had high risk of bias with errors in reporting and design flaws that might have invalidated the results.

At the completion of the review, the EPC investigators graded the strength of evidence for each condition using criteria recommended by the AHRQ Methods Guide for Effectiveness and Comparative Effectiveness Reviews. ${ }^{16}$ Investigators assessed the strength of evidence by evaluating the number of included studies, strength and quality of study design, consistency of results, directness (i.e., the intervention is linked directly with the most important health or ultimate outcomes), precision, and the magnitude of the effect. The evidence was graded as high, moderate, low, or insufficient. High strength of evidence indicates high confidence that the evidence reflects the true effect, and further research is unlikely to change confidence in the estimate of the effect. Moderate strength of evidence indicates moderate confidence that the evidence reflects the true effect, but further research may change confidence in the estimate of the effect or change the estimate. Low strength of evidence indicates low confidence in the reported effect, and further research is expected to change confidence in the estimate of the effect and is likely to change the estimate. A grade of insufficient indicated that the evidence was not available or did not permit a conclusion.

\section{Key Question 1: Utilization of Atypical Antipsychotics}

The 2011 CER report made these conclusions for Key Question 1:

- Atypical antipsychotics have been studied as off-label treatment for the following conditions: ADHD, anxiety, behavioral disturbances of dementia in elderly patients, depression, eating disorders, insomnia, OCD, personality disorder, PTSD, substance use disorders, and Tourette's syndrome.

- The most common atypical antipsychotics prescribed for off-label use are risperidone, quetiapine, and olanzapine, and their use for the treatment of elderly patients has increased in long-term care settings. ${ }^{17-23}$

- One recent study found a decrease in overall use of atypical antipsychotics especially among dementia patients following a 2005 regulatory warning from the FDA and 


\section{TABLE 3 Efficacy of Atypical Antipsychotics by Condition and Strength of Evidence}

\begin{tabular}{|c|c|c|c|c|c|}
\hline & Aripiprazole & Olanzapine & Quetiapine & Risperidone & Ziprasidone \\
\hline \multicolumn{6}{|l|}{ Anxiety } \\
\hline Generalized anxiety disorder & $\mathbf{0}$ & - & ++ & - & - \\
\hline Social phobia & $\mathbf{0}$ & + & - & $\mathbf{0}$ & $\mathbf{0}$ \\
\hline \multicolumn{6}{|c|}{ Attention-deficit hyperactivity disorder } \\
\hline No co-occurring disorders & $\mathbf{0}$ & $\mathbf{0}$ & $\mathbf{0}$ & + & $\mathbf{0}$ \\
\hline Bipolar children & - & $\mathbf{0}$ & $\mathbf{0}$ & $\mathbf{0}$ & $\mathbf{0}$ \\
\hline Mentally retarded children & $\mathbf{0}$ & $\mathbf{0}$ & $\mathbf{0}$ & + & $\mathbf{0}$ \\
\hline \multicolumn{6}{|l|}{ Dementia } \\
\hline Overall & ++ & + & + & ++ & $\mathbf{0}$ \\
\hline Psychosis & + & +- & +- & ++ & $\mathbf{0}$ \\
\hline Agitation & + & ++ & +- & ++ & $\mathbf{0}$ \\
\hline \multicolumn{6}{|l|}{ Depression } \\
\hline MDD augmentation of SSRI/SNRI & $+\boldsymbol{+}^{\mathrm{a}}$ & $\mathbf{t}^{\mathrm{a}}$ & $+\boldsymbol{t}^{\mathrm{a}}$ & ++ & + \\
\hline MDD monotherapy & $\mathbf{0}$ & $\cdot$ & ++ & $\mathbf{0}$ & $\mathbf{0}$ \\
\hline Eating disorders & $\mathbf{0}$ & 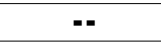 & - & $\mathbf{0}$ & $\mathbf{0}$ \\
\hline Insomnia & $\mathbf{0}$ & $\mathbf{0}$ & - & $\mathbf{0}$ & $\mathbf{0}$ \\
\hline \multicolumn{6}{|l|}{ Obsessive-compulsive disorder } \\
\hline Augmentation of SSRI & $\mathbf{0}$ & + & -- & ++ & - \\
\hline Augmentation of citalopram & $\mathbf{0}$ & $\mathbf{0}$ & + & + & $\mathbf{0}$ \\
\hline \multicolumn{6}{|l|}{ Personality disorder } \\
\hline Borderline & + & +- & + & $\mathbf{0}$ & - \\
\hline Schizotypal & $\mathbf{0}$ & $\mathbf{0}$ & $\mathbf{0}$ & +- & $\mathbf{0}$ \\
\hline Post-traumatic stress disorder & $\mathbf{0}$ & +- & + & ++ & $\mathbf{0}$ \\
\hline \multicolumn{6}{|l|}{ Substance abuse } \\
\hline Alcohol & 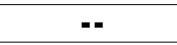 & - & - & $\mathbf{0}$ & $\mathbf{0}$ \\
\hline Cocaine & $\mathbf{0}$ & - & $\mathbf{0}$ & - & $\mathbf{0}$ \\
\hline Methamphetamine & - & 0 & 0 & 0 & 0 \\
\hline Methadone clients & $\mathbf{0}$ & $\mathbf{0}$ & $\mathbf{0}$ & - & $\mathbf{0}$ \\
\hline Tourette's syndrome & $\mathbf{0}$ & $\mathbf{0}$ & $\mathbf{0}$ & + & - \\
\hline \multicolumn{6}{|c|}{ 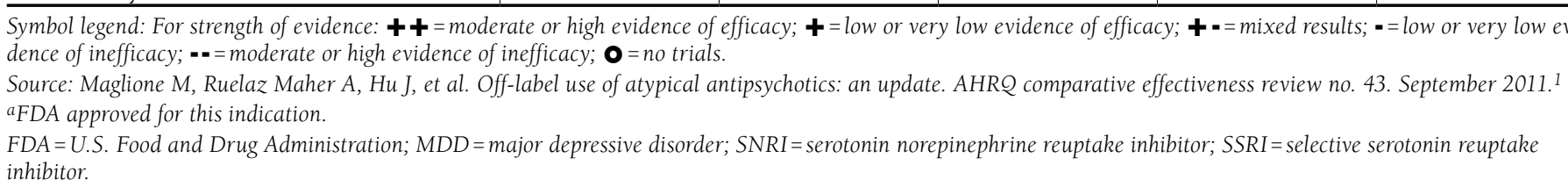 } \\
\hline
\end{tabular}

Health Canada describing increased mortality among elderly people with dementia who were taking atypical antipsychotics. ${ }^{24}$ Atypical antipsychotic medications are also frequently used for the treatment of PTSD by the U.S. Department of Veterans Affairs (VA) health system. ${ }^{25,26}$ Studies in this patient population indicated that quetiapine and risperidone were the atypicals most frquently prescribed off-label at the VA.

- One study of a large psychiatric institution found that quetiapine was often prescribed for a variety of off-label uses; depression and substance abuse were among the most common. ${ }^{27}$

- National trends in the outpatient treatment of children and adolescents over the past decade indicate a sharp increase in the treatment of mental health problems and conditions. ${ }^{28,29}$
- Among children and adolescents, more than $90 \%$ of the antipsychotics prescribed were atypical (most commonly risperidone), and they were used off-label. ${ }^{28,29}$

- The reviewers concluded that, overall, use of atypical antipsychotics for various population subgroups has increased over the last decade.

\section{Key Question 2: Efficacy and Comparative} Effectiveness of Atypical Antipsychotics

The reviewers compared their current findings on efficacy with those of the 2006 CER report and updated the findings (Appendix). No trials of off-label use were found for the 3 most recently FDA-approved atypical antispsychotics (asenapine, iloperidone, and paliperidone). ${ }^{1}$ There were no head-to-head trials of atypicals for MDD, personality disorders, PTSD, or substance abuse (Table 3). 


\section{TABLE 4 Generalized Anxiety Disorder: Pooled PCTs}

\begin{tabular}{|c|c|c|c|c|c|}
\hline Author, Year & Subjects & $\mathrm{N}$ & Treatments & Duration & Outcomes \\
\hline $\begin{array}{l}\text { Bandelow et al. } \\
200939\end{array}$ & $\begin{array}{l}\text { Aged } 18-65 \text { years, diagnosed GAD, HAM-A total } \\
\text { score } \geq 20 \text { with item } 1 \text { and } 2 \text { scores } \geq 2 \text {, MADRS } \\
\text { total score } \leq 16 \text {, CGI-S score } \geq 4 \text { at enrollment and } \\
\text { randomization }\end{array}$ & 873 & $\begin{array}{l}\text { Placebo } \\
\text { Quetiapine } 50-150 \mathrm{mg} \text { per day } \\
\text { Quetiapine } 50 \mathrm{mg} \text { per day } \\
\text { Paroxetine } 20 \mathrm{mg} \text { per day }\end{array}$ & 8 weeks & $\begin{array}{l}\text { \% responders on HAM-A: } \\
\text { Quetiapine vs. placebo-relative } \\
\text { risk }=1.36(95 \% \mathrm{CI}=1.17-1.59)\end{array}$ \\
\hline $\begin{array}{l}\text { Joyce et al. } \\
200840\end{array}$ & Diagnosed GAD & 710 & $\begin{array}{l}\text { Placebo } \\
\text { Quetiapine } 50 \mathrm{mg} \text { per day } \\
\text { Quetiapine } 150 \mathrm{mg} \text { per day }\end{array}$ & 8 weeks & $\begin{array}{l}\text { \% responders on HAM-A: } \\
\text { Quetiapine vs. placebo-relative } \\
\text { risk }=1.02(95 \% \mathrm{CI}=0.85-1.21)\end{array}$ \\
\hline $\begin{array}{l}\text { Merideth et al. } \\
2008^{38}\end{array}$ & $\begin{array}{l}\text { DSM-IV diagnosis of GAD, HAM-A total score } \\
\geq 20 \text { with item } 1 \text { and item } 2 \text { scores } \geq 2, \text { CGI-S } \geq 4 \text {, } \\
\text { MADRS } \leq 16\end{array}$ & 854 & $\begin{array}{l}\text { Placebo } \\
\text { Escitalopram } 10 \mathrm{mg} \text { per day } \\
\text { Quetiapine } 150 \mathrm{mg} \text { per day } \\
\text { Quetiapine } 300 \mathrm{mg} \text { per day }\end{array}$ & 8 weeks & $\begin{array}{l}\text { \% responders on HAM-A: } \\
\text { Quetiapine vs. placebo-relative } \\
\text { risk }=1.46(95 \% \mathrm{CI}=1.21-1.76)\end{array}$ \\
\hline
\end{tabular}

Source: Maglione M, Ruelaz Maher A, Hu J, et al. Off-label use of atypical antipsychotics: an update. AHRQ comparative effectiveness review no. 43. September 2011. ${ }^{1}$ $C I=$ confidence interval; $C G I-S=$ clinical global impression-severity; DSM-IV = Diagnostic and Statistical Manual of Mental Disorders, 4th ed.; GAD =generalized anxiety disorder; HAM-A = Hamilton Anxiety Scale; $m g=$ milligram; MADRS=Montgomery-Asberg Depression Rating Scale; $m g=$ milligrams; PCT=placebo-controlled trial.

\section{ADHD}

ADHD was not included in the previous report, but the update included 3 placebo-controlled trials (PCTs) and 1 active-control trial, ranging from 4 to 6 weeks, for this condition. ${ }^{1,2}$ There were no trials of quetiapine, olanzapine, or ziprasidone for ADHD. Risperidone was superior to placebo in reducing scores on the Children's Aggression Scale-Parent version (CAS-P) in children with no serious co-occurring disorders. ${ }^{30}$ All patients receiving risperidone responded (defined as an improvement of $30 \%$ over their baseline CAS-P scores) versus only $77 \%$ of placebo-treated patients. ${ }^{31}$ In another trial of risperidone versus methylphenidate in mentally retarded children with ADHD, there was a greater reduction in SNAP-IV (Swanson, Nolan, and Pelham teacher $\&$ parent rating scale) scores with risperidone. ${ }^{31}$ Data from 2 trials evaluating aripiprazole (vs. placebo or vs. aripiprazole plus methylphenidate) showed no difference in SNAP-IV scores in children with bipolar disorder or ADHD. ${ }^{32,33}$

\section{Anxiety}

Anxiety disorders were also not included in the previous report., ${ }^{1,2}$ The literature search identified 18 relevant trial reports for the treatment of anxiety with atypical antipsychotics, with Jadad scores ranging from 2 to 5 with a mean score of 3.1. ${ }^{1}$ The 2011 CER update included 15 PCTs evaluating atypical antipsychotics in the treatment of anxiety. ${ }^{1}$ Sample sizes varied widely; follow-up time ranged from same day to 1 year; and most of the PCTs for anxiety reported HAM-A (Hamilton Anxiety Scale) as the primary outcome measure. ${ }^{1}$ Trials that did not use the HAM-A evaluated the use of quetiapine and olanzapine for social anxiety disorder. These trials found olanzapine superior to placebo ${ }^{34}$ and did not find quetiapine superior to placebo. , $^{1,35,36}$

In one previous meta-analysis of quetiapine treatment, monotherapy was significantly superior to placebo for GAD. ${ }^{37}$
Three PCTs of quetiapine monotherapy for GAD were pooled based on their clinical similarities, and a comparison of relative risk of responding on the HAM-A favored quetiapine over placebo (Table 4). ${ }^{38-40}$ All 3 trials had a quetiapine 150 milligram (mg) comparison group, and the pooled estimate of the relative risk of responding on the HAM-A in favor of the quetiapine treatment groups was 1.26 (95\% confidence interval $[C I]=1.02-1.56) .1,38-40$ Another PCT evaluated quetiapine monotherapy as maintenance treatment for GAD and found that it reduced the risk of relapse of anxiety events compared with placebo. ${ }^{41}$ A PCT of ziprasidone reported no difference in the HAM-A score at 8 weeks, compared with placebo. ${ }^{42}$

Augmentation studies were separated from studies of monotherapy. A small $(\mathrm{N}=20)$ study found that quetiapine augmentation of selective serotonin reuptake inhibitor (SSRI) treatment resulted in $60 \%$ responders on the HAM-A versus 30\% with placebo augmentation (not statistically significant). ${ }^{43}$ A similar study with more participants $(\mathrm{N}=409)$ found no statistical difference in HAM-A response rate at 8 weeks. Quetiapine as augmentation of paroxetine for refractory GAD did not provide a significant benefit over placebo augmentation. ${ }^{44}$

There were few head-to-head comparisons, but in a trial of risperidone and paroxetine for panic attacks, significant improvements were reported in the HAM-A for both groups. ${ }^{45,46}$ For the treatment of GAD, at 8 weeks, one trial found 50 or 150 $\mathrm{mg}$ per day quetiapine as effective as paroxetine $20 \mathrm{mg}$ per day, ${ }^{43}$ and another trial found 150 or $300 \mathrm{mg}$ per day quetiapine as effective as $10 \mathrm{mg}$ per day escitalopram. ${ }^{40}$

\section{Dementia}

Although results of previous meta-analyses of atypical antipsychotics in the treatment of behavioral disturbances of dementia in the elderly were mixed, the current review included a new meta-analysis with the previously included trials as well as newer trials. ${ }^{45-48}$ However, the reviewers conducted their own 
review on 37 trials in patients with dementia that compared aripiprazole, olanzapine, quetiapine, and risperidone with placebo and with another active drug. ${ }^{1}$ Of these trials, 18 clinically similar PCTs reporting outcomes at 6-12 weeks were pooled for analysis. ${ }^{1}$ The Jadad scores ranged from 0-5 with a mean score of 3.0; hence, the quality of these trials varied widely. ${ }^{1}$ Outcomes were divided into 3 categories: total/global scores, psychosis, and agitation. Total global score included many psychiatric symptoms such as delusions, anxiety, and apathy as measured by the Neuropsychiatric Inventory (NPI). Psychosis was measured with a focus primarily on delusions and hallucinations by subscales of the Behavioral Pathology in Alzheimer's Disease Rating Scale (BEHAVE-AD), the Brief Psychiatric Rating Scale (BPRS), and NPI. Agitation was measured by subscales of the BEHAVE-AD, BPRS, NPI, and Cohen-Mansfield Agitation Inventory and included physical aggression, verbal aggression, excitability, oppositional behaviors, and excessive motor ability. ${ }^{1}$ A significant difference was observed between atypical antipsychotics (as a class) compared with placebo for all outcomes: total/global scores (standardized mean difference $[\mathrm{SMD}] 0.17$ [95\% CI=0.08-0.25]), psychosis (SMD $0.12[95 \% \mathrm{CI}=0.04-0.19]$ ), and agitation (SMD 0.20 $[95 \% \mathrm{CI}=0.12-0.27]$ ). While the minimum clinically important difference is not known, these effect sizes were generally considered "small" in magnitude. ${ }^{1}$

\section{Depression-MDD}

The 2006 CER report found that when atypicals were used as augmentation to SSRIs, they were not more effective than placebo at 8 weeks, but they led to more rapid improvement in some trials ( 2 to 4 weeks). Although meta-analyses published after 2006 found no statistical difference between specific atypical antipsychotics in increasing response and remission rates, atypicals were found superior to placebo. By 2011, new meta-analyses of trials augmenting SSRIs or serotonin norepinephrine reuptake inhibitors (SNRIs) with atypical antipsychotics showed that several atypicals have efficacy in treatment of depression when used as augmentation. These metaanalyses also showed efficacy for quetiapine monotherapy. In pooled analysis conducted by the reviewers, the relative risk of responding on Hamilton Depression Rating Scale (HAM-D) scores for participants taking quetiapine or risperidone as augmentation was significantly higher than for placebo.

In 3 PCTs reporting the Montgomery-Asberg Depression Rating Scale (MADRS), the relative risk of responding for participants taking aripiprazole was significantly higher than for placebo. In one PCT reporting MADRS, risperidone was statistically superior to placebo. Another PCT that reported MADRS found ziprasidone statistically superior to placebo. The reviewers conducted a meta-analysis of 5 recent trials of quetiapine monotherapy for MDD and found that the relative risk of remitting on the MADRS was statistically superior for quetiapine compared with placebo. In one trial, quetiapine was superior to lithium with respect to HAM-D and MADRS scores.

\section{Eating Disorders}

Off-label use for the treatment of eating disorders was not included in the 2006 CER. In the 2011 update, 5 trials of olanzapine were found; in 3 pooled studies there was no difference between olanzapine and placebo in body mass index (BMI) increase at 1 or 3 months. One trial of quetiapine also reported no statistical difference in BMI increase at 3 months.

\section{Insomnia}

Off-label use for insomnia was not included in the 2006 CER. Recently, one small trial of quetiapine did not report a statistical difference from placebo in sleep outcomes. Two observational studies of olanzapine and 4 of quetiapine found promising improvements in sleep quality and sleep onset.

\section{OCD}

Meta-analysis in the 2006 CER found that atypicals had a clinically important benefit when used as augmentation to SSRIs. Similar findings were reported in 3 published meta-analyses. The 2011 analysis of PCTs reporting Y-BOCS (Yale-Brown Obsessive Compulsive Scale) outcomes showed significant effects for risperidone as augmentation in treatment of refractory patients. Separate pooling for olanzapine could not be conducted, and the difference in effect was not statistically significant versus placebo. Two new trials after the 2006 CER found quetiapine superior to placebo as augmentation to citalopram. One new trial found quetiapine augmentation of an SSRI superior to augmentation with clomipramine. One head-to-head trial of olanzapine versus risperidone as SSRI augmentation for OCD found no differences. Quetiapine had greater efficacy than ziprasidone in another head-to-head trial.

\section{Personality Disorders}

All trials from the 2006 CER reported efficacy of olanzapine and of aripiprazole for BPD. More recently, PCTs of atypicals for treatment of BPD have had heterogeneous outcomes, and meta-analysis could not be performed.

\section{PTSD}

No trials of aripiprazole or ziprasidone for PTSD were found. The 2006 CER reported that atypicals had beneficial results for combat-related PTSD in 3 PCTs with augmentation for PTSD in male veterans. Three PCTs had mixed results for atypical monotherapy in abused women. These trials were not sufficient to conduct meta-analysis. In a meta-analysis of risperidone and olanzapine studies, the results were not separated by drug. This study found atypicals superior to placebo as measured by change in the Clinician Administered PTSD Scale (CAPS) score. In 2011, 5 clinically similar PCTs were pooled based on 
changes in the CAPS score. In 4 trials, risperidone was superior to placebo, and olanzapine was superior to placebo in the other trial. A 3-fold decline in CAPS scores was reported in patients on quetiapine monotherapy compared with patients treated with placebo in another trial. Meta-analysis of risperidone treatment by trial length found that pooled results from at least 12 weeks follow-up were not statistically different from those reported at less than 12 weeks. In another meta-analysis by condition, atypicals showed efficacy in treatment of combatrelated PTSD but not PTSD in abused women.

\section{Substance Abuse}

Although off-label use in the treatment of substance abuse was not covered in the 2006 CER report, the updated CER included 2 PCTs of aripiprazole and 1 of quetiapine that reported the percentage of alcohol abusers completely abstinent during the follow-up period. In pooled analysis, the drugs had insignificant efficacy compared with placebo. Two PCTs of olanzapine and 1 of risperidone in cocaine users were pooled, and no difference in efficacy (as measured by change in the Addiction Severity Index) was found versus placebo. Aripiprazole was inefficacious in reducing use of intravenous amphetamine in 1 PCT and inefficacious in reducing craving for methamphetamine in another PCT. In a PCT of methadone clients, no difference was seen between risperidone and placebo in reducing the use of cocaine or heroin. One trial of aripiprazole versus naltrexone in alcohol abusers found no difference in either mean number of days abstinent nor percentage of participants completely abstinent. ${ }^{1}$ Augmenting naltrexone with quetiapine produced no difference from placebo augmentation in any alcohol use outcomes. The comparison of risperidone versus pergolide found neither more efficacious than placebo in reducing cocaine use.

\section{Tourette's Syndrome}

The 2006 CER found risperidone superior to placebo in 1 small PCT and at least as efficacious as pimozide or clonidine for 8 to 12 weeks of therapy in 3 other trials. One PCT of ziprasidone showed variable efficacy compared with placebo. No new trials of atypicals have been published since the 2006 CER.

\footnotetext{
Key Question 3: Efficacy and Harms with Off-Label Use in Subpopulations and Severity and Subtype of Condition

There were insufficient data to determine which subpopulation would benefit from off-label uses of atypicals. ${ }^{1}$ One study of aripiprazole as adjunct therapy in MDD conducted a subgroup analysis by gender and found no statistically significant difference. Few studies stratified results by age, but none stratified by racial or ethnic group. The reviewers' pooled analysis of combat-related PTSD in men found a mean difference in CAPS of 7.95 (95\% CI = 1.06-14.84) compared with placebo. ${ }^{1}$ Separate publications described the PTSD studies without performing head-to-head comparison of gender effects within a study. The
}

reviewers were not able to conclude whether any observed differences were due to gender or due to the type of PTSD being treated (combat vs. abuse). Due to the varying measures utilized in determining severity of illness, it was not possible to analyze treatment effects by severity of illness across any other condition in this review. Overall, there was insufficient evidence to make conclusions regarding differences in efficacy between subpopulations.

\section{Key Question 4: Comparison of Adverse Effects of Off-Label Use of Atypical Antipsychotics Within the Class and Other Drugs}

Safety data were assessed based on the type of comparisons involved, which included head-to- head, active, and placebo comparisons (Table 5).

\section{Weight Gain}

Weight gain was evaluated in adults and elderly patients taking atypical antipsychotics. In the large CATIE-AD (Clinical Antipsychotic Trials of Intervention Effectiveness-Alzheimer's Disease) trial, elderly placebo patients averaged a monthly weight loss of 0.9 lbs., while patients treated with the various atypical antipsychotics averaged monthly weight gains; 1 pound with olanzapine, 0.7 pounds with quetiapine, or 0.4 pounds with risperidone. ${ }^{49}$ Elderly patients with a BMI less than 25 at the start of the cohort study experienced weight gain more commonly while on olanzapine than risperidone or conventional antipsychotics. Meta-analysis of placebo comparisons revealed that weight gain was more common in elderly patients treated with olanzapine and risperidone compared with placebo. ${ }^{1}$ The review included a single trial evaluating the effects on weight gain among adults aged 18 to 64 years and again found weight gain to be more common among olanzapine patients than ziprasidone patients. In this age group, olanzapine was more commonly associated with weight gain than was conventional treatment with antipsychotics or treatment with mood stabilizers. ${ }^{1}$ Overall, weight gain was more common for aripiprazole-treated patients when compared with patients treated with conventional antipsychotics. The reviewers' metaanalysis found that weight gain was less common in patients taking placebo compared with aripiprazole, olanzapine, quetiapine, and risperidone. ${ }^{1}$ As in the 2006 report, high-strength evidence across multiple trials showed greater weight gain with olanzapine compared with placebo, conventional antipsychotics, or other atypical antipsychotics. ${ }^{1,2}$ Although the strength of evidence was stronger in the update, the reviewers commented that the evidence was not as robust as in the 2006 report. In nonelderly adults, the association of olanzapine, risperidone, quetiapine, and aripiprazole with weight gain was statistically significant versus placebo. An association was found for weight gain with ziprasidone therapy, but these data were not statistically significant. 


\section{TABLE 5 Safety of Atypical Antipsychotics for Off-Label Use ${ }^{a}$}

Adverse Event Head-to-Head Comparisons

Weight gain- In 1 large trial

elderly

patients

(CATIE-AD), patients who

were treated with olanzap- ine, quetiapine, or risperi-

done averaged a monthly

gain of $1.0,0.7$, and 0.4

lbs, respectively, compared

with a monthly weight

loss of $0.9 \mathrm{lbs}$ for placebo patients

Weight gainto 64 years

\section{Active Comparisons}

More common in patients taking olanzap-

ine than risperidone or conventional anti-

psychotics, particularly if BMI was less

than 25 at baseline, according to a large

cohort study. adults aged 18
More common in olanzapine patients than ziprasidone patients in 1 trial.
More common among patients taking olanzapine than patients taking conventional antipsychotics in 3 trials.

More common in patients taking aripiprazole than patients taking conventional antipsychotics in 1 trial.

More common among patients taking olanzapine than patients taking mood stabilizers in 2 trials.

\begin{tabular}{l|l}
\hline $\begin{array}{l}\text { Weight gain- } \\
\text { children and } \\
\text { adolescents }\end{array}$ & No head-to-head studies. \\
\hline $\begin{array}{l}\text { Mortality- } \\
\text { elderly }\end{array}$ & $\begin{array}{l}\text { No difference between } \\
\text { olanzapine and risperidone } \\
\text { patients }\end{array}$ \\
$\begin{array}{l}\text { according to a meta-analy- } \\
\text { sis of } 6 \text { trials of olanzapine } \\
\text { published in 2006. }\end{array}$
\end{tabular}

\begin{tabular}{l|l} 
while 2 found no statistical difference in \\
mortality between the drug classes.
\end{tabular}

\begin{tabular}{|c|c|c|c|}
\hline & & & $\begin{array}{l}\text { There are no trials or large observational studies of ziprasidone } \\
\text { in this population; therefore, we cannot make conclusions } \\
\text { regarding safety here. }\end{array}$ \\
\hline $\begin{array}{l}\text { Endocrine/ } \\
\text { diabetes- } \\
\text { elderly } \\
\text { patients }\end{array}$ & No evidence reported. & No evidence reported. & $\begin{array}{l}\text { No difference in endocrine events in risperidone patients in } 1 \\
\text { PCT. } \\
\text { Regarding diabetes, risk was elevated but not statistically sig- } \\
\text { nificant in one industry-sponsored cohort study of olanzapine } \\
\text { patients. }\end{array}$ \\
\hline $\begin{array}{l}\text { Endocrine/ } \\
\text { diabetes- } \\
\text { adults aged } 18 \\
\text { to } 64 \text { years }\end{array}$ & $\begin{array}{l}\text { Diabetes more common in } \\
\text { patients taking olanzapine } \\
\text { than patients taking ris- } \\
\text { peridone in } 1 \text { trial. }\end{array}$ & No evidence reported. & $\begin{array}{l}\text { Endocrine events more common in patients taking quetiapine, } \\
\text { risperidone, and ziprasidone in } 1 \text { PCT each. More common in } \\
\text { olanzapine in } 2 \text { pooled PCTs. } \\
\text { Diabetes more common in patients taking quetiapine in } 6 \\
\text { pooled PCTs; however, the pooled odds ratio was elevated at } \\
1.47 \text { but not statistically significant. More common in olanza- } \\
\text { pine patients in } 1 \text { PCT; the odds ratio of } 5.14 \text { was not statisti- } \\
\text { cally significant, with very wide confidence intervals ( } 0.6 \text { to } \\
244) \text {. } \\
\text { Lower odds of diabetes in risperidone patients in one large } \\
\text { observational study. }\end{array}$ \\
\hline $\begin{array}{l}\text { CVA- } \\
\text { elderly } \\
\text { patients }\end{array}$ & No evidence reported. & $\begin{array}{l}\text { Hospitalization for CVA was increased in } \\
\text { the first week after initiation of conven- } \\
\text { tional antipsychotics, but not for initiation } \\
\text { of atypicals in a large cohort study. }\end{array}$ & $\begin{array}{l}\text { More common in risperidone patients than placebo accord- } \\
\text { ing to } 4 \text { PCTs pooled by the manufacturer. In our new meta- } \\
\text { analysis of PCTs, risperidone was the only drug associated with } \\
\text { an increase. } \\
\text { More common in olanzapine than placebo according to } 5 \text { PCTs } \\
\text { pooled by the manufacturer. }\end{array}$ \\
\hline $\begin{array}{l}\text { EPS- } \\
\text { elderly } \\
\text { patients }\end{array}$ & $\begin{array}{l}\text { More common in patients } \\
\text { taking aripiprazole and } \\
\text { risperidone than patients } \\
\text { taking quetiapine in } 1 \\
\text { large trial (CATIE-AD). }\end{array}$ & No evidence reported. & $\begin{array}{l}\text { More common in patients taking risperidone, according to our } \\
\text { meta-analysis. Quetiapine and aripiprazole were not associated } \\
\text { with an increase. } \\
\text { More common in olanzapine in } 1 \text { PCT. }\end{array}$ \\
\hline
\end{tabular}

More common in patients taking aripiprazole, olanzapine, quetiapine, and risperidone than placebo according to our metaanalysis.

More common in patients taking risperidone in 2 PCTs. No difference in 1 small PCT of ziprasidone.

Difference in risk for death was small but statistically significant for atypicals, according to a 2006 meta-analysis, which remains the best available estimate. Sensitivity analyses found no difference between drugs in the class.

Patients taking atypicals had higher odds of mortality than those taking no antipsychotics in the 2 cohort studies that made that comparison.

large cohort studies compared morta ity in elderly patients taking atypical an conventional antipsychotics. 4 of these studies found a significantly higher rate of death with conventional antipsychotics, while 2 found no statistical difference in regarding safety here.

PCT patients. olanzapine in 2 pooled PCTs. 1.47 but not statistically significant. More common in olanzapine patients in 1 PCT; the odds ratio of 5.14 was not statistically significant, with very wide confidence intervals ( 0.6 to

Lower odds of diabetes in risperidone patients in one large observational study.

ing to 4 PCTs pooled by the manufacturer. In our new metaanalysis of PCTs, risperidone was the only drug associated with More common in olanzapine than placebo according to 5 PCTs pooled by the manufacturer with an increase. 
Summary of the Comparative Effectiveness Review on Off-Label Use of Atypical Antipsychotics

\section{TABLE 5 Safety of Atypical Antipsychotics for Off-Label Use ${ }^{a}$ (continued)}

\begin{tabular}{|c|c|c|c|}
\hline Adverse Event & Head-to-Head Comparisons & Active Comparisons & Placebo Comparisons \\
\hline $\begin{array}{l}\text { EPS- } \\
\text { adults aged } \\
18 \text { to } 64 \text { years }\end{array}$ & No evidence reported. & $\begin{array}{l}\text { Less likely in patients taking quetiapine } \\
\text { than mood stabilizers in } 1 \text { small trial. } \\
\text { Less likely in patients taking olanzapine } \\
\text { or aripiprazole than patients taking con- } \\
\text { ventional antipsychotics in } 1 \text { trial each. }\end{array}$ & $\begin{array}{l}\text { More common in patients taking aripiprazole, quetiapine, and } \\
\text { ziprasidone than placebo according to our meta-analysis. }\end{array}$ \\
\hline $\begin{array}{l}\text { Sedation- } \\
\text { elderly } \\
\text { patients }\end{array}$ & $\begin{array}{l}\text { More common in elderly } \\
\text { patients taking olanza- } \\
\text { pine or quetiapine than } \\
\text { risperidone according to } \\
\text { our analysis, but not quite } \\
\text { statistically significant. }\end{array}$ & $\begin{array}{l}\text { No difference in } 1 \text { trial of olanzapine vs. } \\
\text { benzodiazepines. } \\
\text { No difference in } 3 \text { trials of olanzapine } \\
\text { and } 3 \text { of risperidone vs. conventional } \\
\text { antipsychotics. }\end{array}$ & $\begin{array}{l}\text { More common in patients taking aripiprazole, olanzapine, que- } \\
\text { tiapine, and risperidone than placebo according to our meta- } \\
\text { analysis. }\end{array}$ \\
\hline $\begin{array}{l}\text { Sedation- } \\
\text { children and } \\
\text { adolescents }\end{array}$ & No head-to-head trials. & $\begin{array}{l}\text { No difference in } 1 \text { small trial of clonidine } \\
\text { vs. risperidone. More patients on halo- } \\
\text { peridol than risperidone reported sleep } \\
\text { problems in one trial. }\end{array}$ & $\begin{array}{l}\text { Less common in aripiprazole patients than placebo patients } \\
\text { in } 1 \text { PCT. No difference from placebo in } 1 \text { small PCT of } \\
\text { ziprasidone. }\end{array}$ \\
\hline $\begin{array}{l}\text { Sedation- } \\
\text { adults aged } \\
18 \text { to } 64 \text { years }\end{array}$ & $\begin{array}{l}\text { More common in patients } \\
\text { taking quetiapine than ris- } \\
\text { peridone in } 2 \text { trials. } \\
\text { No difference in } 1 \text { trial of } \\
\text { risperidone vs. olanzapine. }\end{array}$ & $\begin{array}{l}\text { Olanzapine patients had higher odds than } \\
\text { mood stabilizer patients in } 2 \text { trials. } \\
\text { More common in olanzapine and quetia- } \\
\text { pine patients than SSRI patients in } 3 \text { and } \\
2 \text { trials, respectively. } \\
\text { Olanzapine patients had lower odds than } \\
\text { patients taking conventional antipsychot- } \\
\text { ics in our pooled analysis of } 3 \text { trials. }\end{array}$ & $\begin{array}{l}\text { More common in patients taking aripiprazole, olanzapine, } \\
\text { quetiapine, risperidone, and ziprasidone than placebo in our } \\
\text { meta-analysis. }\end{array}$ \\
\hline
\end{tabular}

Source: Maglione M, Ruelaz Maher A, Hu J, et al. Off-label use of atypical antipsychotics: an update. AHRQ comparative effectiveness review no. 43. September 2011. ${ }^{1}$ aSome of the text included in this table is identical to the source text.

$B M I=$ body mass index; CATIE-AD = Clinical Antipsychotic Trials of Intervention Effectiveness-Alzheimer's Disease; $C V A=$ cerebrovascular accident; EPS=extrapyramidal symptoms; lbs = pounds; $P C T=$ placebo-controlled trial; $S S R I=$ selective serotonin reuptake inhibitor.

\section{Metabolic Symptoms}

The occurrence of endocrine events including diabetes among adults (aged 18-64 years) and the elderly was a new focus included in the 2011 CER. ${ }^{1}$ Among elderly patients, no difference in risk was found comparing placebo with risperidone treatment, and an observed elevated risk of diabetes for olanzapine treatment was not significantly associated with treatment but rather depended on elevated glucose levels at baseline. In adults aged 18 to 64 years, olanzapine was associated with a greater risk of diabetes when compared with risperidone, and lower odds of diabetes were reported in risperidone patients compared with placebo in 1 large observational study. ${ }^{50-53}$ Six pooled PCTs found diabetes to be more common among quetiapine-treated patients, but the elevated pooled odds ratio of 1.47 (95\% CI=0.71-3.28) for these patients was not statistically significant. ${ }^{1}$ The updated report noted an emerging safety signal of an increase in urinary tract symptoms with atypical antipsychotics. ${ }^{1}$ This increase was noted in older adults with behavioral disturbances of dementia treated with atypical antipsychotics as compared with placebo-treated patients.

\section{Extrapyramidal Symptoms}

Extrapyramidal symptoms (EPS), including acute dystonic reactions, pseudoparkinsonism, and akathisia, were examined in the recent review in adults and elderly patients treated with atypical antipsychotics. The large CATIE-AD trial found symptoms to be more common in elderly patients taking aripiprazole and risperidone than in those taking quetiapine..$^{50}$ In the CATIE-AD trial, EPS were more common with olanzapine and risperidone than quetiapine. ${ }^{49}$ This trial concluded that all 3 of these therapies were associated with cognitive decline in patients with dementia who were treated with these drugs. Meta-analysis conducted by the reviewers revealed that EPS were more common in elderly patients on risperidone compared with placebo, but quetiapine and aripiprazole were not associated with increased EPS. ${ }^{1}$ The association of olanzapine and risperidone with an increase in extrapyramidal signs or symptoms versus placebo had moderate strength of evidence. In a group of another 7 studies that were evaluated via pooled analysis in this review, quetiapine was again associated with EPS. ${ }^{1}$

\section{Mortality}

Data from meta-analyses were found to be of high strength for the association of atypical antipsychotics with an increased risk of death among the elderly with agitation and dementia. ${ }^{1}$ For risperidone, this outcome may be related to an increased risk of stroke. A new finding in this update is the stronger evidence that conventional antipsychotics also increase the 
risk of death in similar patients, perhaps to the same or greater degree than atypical antipsychotics. This finding is qualified by a moderate strength of evidence, relying on data mostly from observational studies of high quality.

With respect to mortality among the elderly, no difference was found in the head-to-head comparison for olanzapine versus risperidone. Results from active comparisons of atypical and conventional antipsychotics were split, with 4 studies reporting a significantly higher rate of death for conventional antipsychotics and 2 studies reporting no statistical difference in mortality. ${ }^{1}$ Such findings were difficult to assess in the review. The 2006 meta-analysis, which found a small but statistically significant difference in risk for death for atypical antipsychotics, remains the best available estimate of their effect on mortality. ${ }^{2}$

\section{Sedation}

Sedation is another adverse effect commonly associated with atypical antipsychotics. The reviewers analyzed data on sedation for elderly patients taking olanzapine and quetiapine. Sedation was more common in these patients compared with risperidone, but this difference was not statistically significant. ${ }^{1}$ In this elderly population, there was no difference for olanzapine versus benzodiazepines or compared with conventional antipsychotics. Among the elderly, no difference in the risk of sedation was seen for risperidone therapy versus conventional antipsychotics. Meta-analysis of PCTs also found that aripiprazole, olanzapine, quetiapine, and risperidone were each associated with both sedation and fatigue in patients with dementia. Similarly, increases in sedation and fatigue were found for ziprasidone versus placebo in adults aged 18 to 64 years. ${ }^{1}$ In adults in that age group, sedation was more common with quetiapine versus risperidone, and no differences were found in a comparison of olanzapine with risperidone. Olanzapinetreated patients did have higher odds of experiencing sedation symptoms than those taking mood stabilizers, but the odds were lower for olanzapine patients when compared with those taking conventional antipsychotics in a pooled analysis of the data. ${ }^{1}$ Sedation was more common in patients taking SSRIs compared with olanzapine and quetiapine therapy. Among children and adolescents, no difference in sedation was observed in a small trial of clonidine versus risperidone, but more patients reported sleep problems on haloperidol compared with risperidone. Compared with placebo, sedation was less common in aripiprazole-treated patients, and no difference was observed with ziprasidone treatment.

\section{Cerebrovascular Accidents}

The updated summary included data on cerebrovascular accidents (CVAs) among elderly patients. Hospitalization for CVA increased in the first week after the start of therapy with conventional antipsychotics but not with atypicals. ${ }^{1}$ CVAs were more common in elderly risperidone patients than in placebotreated individuals. This finding was based on data from 4 pooled studies and from a meta-analysis of PCTs. More CVAs were also observed for olanzapine compared with placebo. ${ }^{1}$ No studies of any drug or condition reported on CVA in younger adults.

\section{Key Question 5: Dosage and Treatment} Duration for Off-Label Indications

Conclusions could not be drawn by the reviewers as to the minimum dose needed to achieve efficacy, since very few studies compared doses of atypical antipsychotic medications. Most patients enrolled in trials took a wide range of doses, complicating the establishment of conclusions by the investigators. Meta-analysis was conducted using the percentage of remitters and responders according to the MADRS as an outcome and found no statistical difference for $150 \mathrm{mg}$ quetiapine daily augmentation versus augmentation with $300 \mathrm{mg}$ for inadequate responders to SSRI with MDD. ${ }^{1}$ Trial data for duration of treatment and outcomes seemed the same for PTSD, eating disorders, and BPD, regardless of the follow-up time used.

\section{Study Limitations and Directions for Future Research} Unidentified, unpublished, or excluded studies might have reported different results from those included in this review. The meta-analysis, particularly for behavioral disturbances of dementia, includes broad heterogeneity across patients and treatment circumstances. Furthermore, the reviewers noted the possibility of publication bias in the studies. The studies used variable definitions and measures of agitation, which complicates the clinical interpretation and application of these findings. ${ }^{1}$ Comparisons of atypical antipsychotics with nonpharmacological therapy were not made. Very few studies were funded with federal grants, and most were privately funded. However, the government-sponsored CATIE-AD study reported results consistent with the industry-sponsored studies, increasing confidence in the conclusions regarding atypical antipsychotic medications for elderly patients with dementia. ${ }^{49}$ Future research should include more federally funded studies, head-to-head comparisons between the various atypical antipsychotic medications, and standardized definitions of both treatments and response. More trials examining different doses of other atypicals for MDD would help guide clinicians in treating this population. In addition, more dosage trials for treating such conditions as OCD, PTSD, and GAD would allow for pooling and comparisons of results. ${ }^{1}$ Lastly, some studies on the use of medications for insomnia will surely augment the strength of evidence available for this topic, since only 1 small trial was previously found.

\section{Conclusions}

The 2011 AHRQ-sponsored review addressed many uses for atypical antipsychotics in conditions that were not covered in the previous report. The 2011 CER found high strength of 
evidence of small but statistically significant benefits for the use of aripiprazole, olanzapine, and risperidone in elderly patients for management of behavioral symptoms associated with dementia. There was moderate strength of evidence that aripiprazole, quetiapine, and risperidone have efficacy as augmentation to SSRIs/SNRIs for MDD and that quetiapine had efficacy as monotherapy for MDD. Olanzapine did not have efficacy as monotherapy for MDD, and that finding was supported by moderate strength of evidence.

Moderate strength of evidence supported efficacy for risperidone treatment improving OCD symptoms when used as an adjunct to SSRI in treatment-refractory patients and in reducing combat-related PTSD symptoms when used as an adjunct to primary medication. Additional moderate strength of evidence was found for quetiapine efficacy as treatment for GAD. The lack of efficacy for olanzapine in increasing BMI among patients with eating disorders was also supported by moderate strength of evidence. Finally, moderate strength of evidence was collected demonstrating that aripiprazole was not efficacious in treating alcohol abuse/dependence.

The rest of the strength of evidence was low or very low. Low strength of evidence showed that olanzapine and ziprasidone may have efficacy as augmentation to SSRIs/SNRIs for MDD. In addition, low strength of evidence showed that olanzapine may have efficacy in improving OCD symptoms when used as an adjunct to SSRI in treatment-refractory patients and that quetiapine may be efficacious as augmentation to citalopram in patients with OCD. Furthermore, quetiapine was more efficacious than ziprasidone and clomipramine for the treatment of OCD. For the treatment of BPD, there was low strength of evidence from 2 trials that found aripriprazole was efficacious. Risperidone had mixed results when used to treat SPD in 2 small trials, and the strength of evidence was low. Regarding Tourette's syndrome, treatment with risperidone was at least as efficacious as pimozide or clonidine.

The reviewers evaluated different types of ADHD and found low strength of evidence that for ADHD without co-occurring disorders, risperidone therapy may be efficacious in the treatment of children. Low strength of evidence was found for the lack of efficacy from aripiprazole in reducing ADHD symptoms in children with bipolar disorder. Low strength of evidence supported the superiority of risperidone treatment over methylphenidate in treating ADHD symptoms in mentally retarded children.

Quetiapine was not efficacious (low strength of evidence) in increasing BMI among patients with eating disorders. The lack of efficacy found for quetiapine treatment for alcohol abuse/ dependence was also supported with low strength of evidence. For treatment of cocaine abuse/dependence, low strength of evidence showed that olanzapine was not efficacious. For other types of substance abuse, low strength of evidence showed that aripiprazole was inefficacious in treating methamphetamine abuse/dependence and that risperidone is an inefficacious adjunct to methadone maintenance.

The remaining evidence evaluated in the 2011 review was considered to be of very low strength. Very low strength of evidence supported the finding that risperidone may be efficacious as augmentation to citalopram in OCD. Additional data of very low strength of evidence for the treatment of BPD showed that olanzapine had mixed results in 7 trials; quetiapine was efficacious in 1 trial; and ziprasidone was not efficacious in 1 trial. In addition, evidence of very low strength was found for the inefficacy of quetiapine in treating insomnia.

The updated 2011 review contained additional data from recently published scientific literature on the comparative benefits and adverse effects of the off-label use of atypical antipsychotics. The findings demonstrated that off-label use of antipsychotics improved symptoms for various conditions, such as agitation among elderly patients with dementia. In this condition, the lack of effective options has led to wide use of atypical antipsychotics. Evidence is still needed for ways to balance the prevention of symptoms through the use of atypical antipsychotics with the risk of serious adverse effects, such as stroke or death among elderly patients. 
Commentary: Managed Care Perspective on Comparative Effectiveness

Research on Off-Label Uses of Atypical Antipsychotics

Sleep: At What Cost?

Our nation is in a battle for sleep. More than one-third of Americans report having problems sleeping, and a recent national consumer survey on sleep found that a significant portion of Americans are bringing more and more technology into the bedroom, with activities such as texting in the bedroom in the hour prior to sleep associated with poorer self-assessed sleep quality. ${ }^{54}$ Over the past several decades, the pursuit of effective drug therapy by both patients and providers has been vigorous, with nonpharmacologic treatments including cognitive behavioral therapy and improvement in sleep hygiene often taking a secondary role.

Clinicians might be amazed to learn that in the 2011 AHRQ Comparative Effectiveness Review (CER) of off-label uses of atypical antipsychotics reviewers found just 1 study meeting stringent evidence-based inclusion and exclusion criteria that evaluated the safety and effectiveness of an atypical antipsychotic (quetiapine) for the treatment of insomnia. In that 13-patient trial, there was not a statistically significant difference, compared with the use of placebo, in sleep outcomes. While the evidence-limited as it is-is not supportive of the use of atypicals for sleep, clinicians who are utilizing them in clinical practice for this off-label use may argue for "real-world effectiveness." But, given the risks identified in the review, particularly those of rapid weight gain (present even with low doses), akathisia, and extrapyramidal symptoms, it is hard to justify a prescribing practice that is not supported by evidence of benefit but that is supported by evidence of harm. For improving sleep problems, moving the smart phone, texting, laptops, and tablet computers out of the bedroom and going back to the basics with sleep hygiene certainly represent a less risky initial approach to such a common problem.

\section{A Tricky Balance: Weighing the Risks and Benefits of Treatment of Agitated Patients with Dementia with Atypical Antipsychotics}

Pharmacists in a variety of inpatient and ambulatory settings are frequently called on by prescribers and caregivers to assist with management of agitation in older adults with dementia. Often, agitation and inability to manage behavioral problems associated with dementia drive a need for transition from either home to assisted living facility or from assisted living facility into a more supervised setting. Safe and effective pharmacotherapy for agitated patients with dementia is thus a frequent request to both prescribers and pharmacists from caregivers who are experiencing extreme caregiving stress. Unfortunately, it is the lack of the medications' ability - in this case atypical antipsychotics - to meet both of these criteria that often (and should always) result in significant family and prescriber discussion regarding the risks and benefits of therapy with atypical antipsychotics.

The careful assessment in the 2011 AHRQ CER of the off-label use of atypical agents for the treatment of agitation in dementia revealed the intricacies of this drug class, as there was significant variation in effect among the atypicals that have been studied, with significant variation as well in the quality of the studies with various atypicals. Compared with the data available in 2006, there has been a strengthening of the evidence to support a small magnitude of effectiveness in the treatment of agitation in dementia for aripiprazole, olanzapine, and risperidone overall when compared with placebo. Specifically for patients with dementia and psychosis, evidence supports benefit over placebo with the use of risperidone, but not with aripiprazole.

With evidence of benefit, while small in magnitude, it is then important to weigh that benefit with the risk of harm. The black box that was applied in 2005 to atypical antipsychotics warning of an increased risk of death in these patients certainly gives clinicians pause when carefully evaluating a patient for treatment. The CER further states that the number needed to harm for increased risk of stroke with risperidone is 56 , although both risperidone and olanzapine were significantly more likely to result in a negative outcome than aripiprazole or quetiapine. ${ }^{55}$ In addition to this risk, there was an increased risk of weight gain (olanzapine and risperidone); anticholinergic effects (olanzapine); sedation and fatigue (aripiprazole, olanzapine, quetiapine, risperidone); extrapyramidal symptoms (olanzapine and risperidone); and urinary tract symptoms (risperidone, quetiapine, olanzapine). Finally, of significant concern is the association of the use of olanzapine, quetiapine, and risperidone with an increased cognitive decline-the very thing that we are attempting to avoid in these patients.

In summary, use of atypical antipsychotics in agitated patients with dementia is multifactorial, with individual patient characteristics and behavioral consequences shifting the balance of risk and benefit. Furthermore, the selection of a particular agent and the objective documentation of benefit in the trials conducted with atypical antipsychotics may affect the use of these therapies. For each patient, an individual assessment and documentation of risks and benefits of therapy is necessary to making the most appropriate decision for the individual.

Karen Gunning, PharmD 


\section{REFERENCES}

1. Maglione M, Ruelaz Maher A, Hu J, et al. Off-label use of atypical antipsychotics: an update. Comparative effectiveness review no. 43. (Prepared by the Southern California Evidence-Based Practice Center under Contract No. HHSA290-2007-10062-1.) Rockville, MD: Agency for Healthcare Research and Quality. September 2011. Available at: http://effectivehealthcare.ahrq. gov/ehc/products/150/778/CER43_Off-LabelAntipsychotics_20110928.pdf. Accessed June 29, 2012

2. Shekelle P, Maglione M, Bagley S, et al. Efficacy and comparative effectiveness of off-label use of atypical antipsychotics. Comparative effectiveness review no. 6. (Prepared by the Southern California/RAND Evidence-Based Practice Center under Contract No. 290-02-0003.) Rockville, MD: Agency for Healthcare Research and Quality. January 2007. Available at: http://effectivehealthcare.ahrq.gov/ehc/products/5/63/Atypical_Antipsychotics_Final_ Report.pdf. Accessed June 29, 2012.

3. National Institute of Mental Health. Health topics: anxiety disorders. 2008. Available at: http://www.nimh.nih.gov/health/topics/anxiety-disorders/index.shtml. Accessed June 29, 2012.

4. Kessler RC, Chiu WT, Demler O, Merikangas KR, Walters EE. Prevalence, severity, and comorbidity of 12-month DSM-IV disorders in the National Comorbidity Survey Replication. Arch GenPsychiatry. 2005;62(6):617-27. Available at: http://www.ncbi.nlm.nih.gov/pmc/articles/PMC2847357/pdf/ nihmsl76704.pdf. Accessed June 29, 2012

5. Hyman SE, Rudorfer MV. Anxiety disorder. In: Dale DC, Federman DD, eds. Scientific American Medicine. Vol. 3. New York: Healtheon/WebMD Corp.;2000:Sect.13,Subsect. VIII

6. Rayner AV,O'Brien JG, Schoenbachler B. Behavior disorders of dementia: recognition and treatment. Am Fam Physician. 2006;73(4):647-52. Available at: http://www.aafp.org/afp/2006/0215/p647.pdf. Accessed June 29, 2012.

7. National Institute of Mental Health. Health topics: depression. 2008. Available at: http://www.nimh.nih.gov/health/topics/depression/index.shtml Accessed June 29, 2012.

8. American Psychiatric Association. The Diagnostic and Statistical Manual of Mental Disorders. Text rev. 4th ed. Washington, DC: American Psychiatric Association; 2000

9. Practice guideline for the treatment of patients with major depressive disorder (revision). American Psychiatric Association. Am J Psychiatry. 2000;157(4 Suppl):1-45.

10. Rothschild AJ. Challenges in the treatment of depression with psychotic features. Biol Psychiatry. 2003;53(8):680-90.

11. Anderson AE. Eating disorders in males: Critical questions. In Lemberg, R, ed. Controlling Eating Disorders with Facts, Advice and Resources. Phoenix, AZ: Oryx Press;1992:20-28.

12. Rajput V, Bromley SM. Chronic Insomnia: a practical review. Am Fam Physician. 1999;60(5):1431-38. Available at: www.aafp.org/ afp/991001ap/1431.html. Accessed June 29, 2012.

13. National Institute of Mental Health. Health topics: obsessive-compulsive disorder (OCD). 2008. Available at: http://www.nimh.nih.gov/health/topics/ obsessive-compulsive-disorder-ocd/index.shtml. Accessed June 29, 2012.

14. National Institute of Mental Health. Health topics: post-traumatic stress disorder (PTSD). 2008. Available at: http://www.nimh.nih.gov/health/topics/post-traumatic-stress-disorder-ptsd/index.shtml. Accessed June 29, 2012.

15. Jadad AR, Moore RA, Carroll D, et al. Assessing the quality of reports of randomized clinical trials: is blinding necessary? Control Clin Trials. 1996;17(1):1-12.

16. Agency for Healthcare Research and Quality. Methods guide for effectiveness and comparative effectiveness reviews. AHRQ publication no. 10(12)-EHC063-EF. Rockville, MD: Agency for Healthcare Research and Quality. April 2012. Available at: http://www.effectivehealthcare.ahrq.gov/ ehc/products/60/318/MethodsGuide_Prepublication-Draft_20120523.pdf. Accessed June 29, 2012.
17. Hermann RC, Yang D, Ettner SL, Marcus SC, Yoon C, Abraham M. Prescription of antipsychotic drugs by office-based physicians in the United States, 1989-1997. Psychiatr Serv. 2002;53(4):425-30. Available at: http:// ps.psychiatryonline.org/data/Journals/PSS/4346/425.pdf. Accessed June 29, 2012.

18. Aparasu RR, Bhatara V, Gupta S. U.S. national trends in the use of antipsychotics during office visits, 1998-2002. Ann Clin Psychiatry. 2005;17(3):147-52.

19. Aparasu RR, Jano E, Bhatara V. Concomitant antipsychotic prescribing in US outpatient settings. Res Social Adm Pharm. 2009;5(3):234-4l.

20. Van Brunt DL, Gibson PJ, Ramsey JL, Obenchain R. Outpatient use of major antipsychotic drugs in ambulatory care settings in the United States, 1997-2000. MedGenMed. 2003;5(3):16. Available at: http://www.medscape com/viewarticle/458984. Accessed June 29, 2012.

21. Sankaranarayanan J, Puumala SE. Antipsychotic use at adult ambulatory care visits by patients with mental health disorders in the United States, 1996-2003: national estimates and associated factors. Clin Ther. 2007;29(4):723-41.

22. Sankaranarayanan J, Puumala SE. Epidemiology and characteristics of emergency departments visits by US adults with psychiatric disorder and antipsychotic mention from 2000 to 2004. Curr Med Res Opin. 2007;23(6):1375-85.

23. Alexander GC, Gallagher SA, Mascola A, Moloney RM, Stafford RS. Increasing off-label use of antipsychotic medications in the United States, 1995-2008. Pharmacoepidemiol Drug Saf. 2011;20(2):177-84. Available at: http://www.ncbi.nlm.nih.gov/pmc/articles/PMC3069498/pdf/nihms-275845. pdf. Accessed June 29, 2012.

24. Dorsey ER, Rabbani A, Gallagher SA, Conti R, Alexander GC. Impact of FDA black box advisory on antipsychotic medication use. Arch Intern Med. 2010;170(1):96-103. Available at: http://archinte.jamanetwork.com/article. aspx?doi=10.1001/archinternmed.2009.456. Accessed June 29, 2012.

25. Mellman TA, Clark RE, Peacock WJ. Prescribing patterns for patients with posttraumatic stress disorder. Psychiatr Serv. 2003;54(12):1618-21. Available at: http://ps.psychiatryonline.org/data/Journals/PSS/3603/1618. pdf. Accessed June 29, 2012.

26. Leslie DL, Mohamed S, Rosenheck RA. Off-label use of antipsychotic medications in the department of Veterans Affairs health care system. Psychiatr Serv. 2009;60(9):1175-81. Available at: http://ps.psychiatryonline. org/data/Journals/PSS/3889/09ps1175.pdf. Accessed May 14, 2012.

27. Philip NS, Mello K, Carpenter LL, et al. Patterns of quetiapine use in psychiatric inpatients: An examination of off-label use. Ann Clin Psychiatry. 2008;20(1):15-20.

28. Olfson M, Blanco C, Liu L, et al. National trends in the outpatient treatment of children and adolescents with antipsychotic drugs. Arch Gen Psychiatry. 2006;63(6):679-85. Available at: http://archpsyc.jamanetwork. com/article.aspx?doi=10.1001/archpsyc.63.6.679. Accessed June 29, 2012

29. Aparasu RR, Bhatara V. Patterns and determinants of antipsychotic prescribing in children and adolescents, 2003-2004. Curr Med Res Opin. 2007;23(1):49-56.

30. Armenteros JL, Lewis JE, Davalos M. Risperidone augmentation for treatment-resistant aggression in attention-deficit/hyperactivity disorder: a placebo-controlled pilot study. J Am Acad Child Adolesc Psychiatry. 2007:46(5):558-65.

31. Correia Filho AG, Bodanese R, Silva TL, Alvares JP, Aman M, Rohde LA. Comparison of risperidone and methylphenidate for reducing ADHD symptoms in children and adolescents with moderate mental retardation. J Am Acad Child Adolesc Psychiatry. 2005;44(8):748-55.

32. Tramontina S, Zeni CP, Ketzer CR, Pheula GF, Narvaez J, Rohde LA. Aripiprazole in children and adolescents with bipolar disorder comorbid with attention-deficit/hyperactivity disorder: a pilot randomized clinical trial. J Clin Psychiatry. 2009;70(5):756-64. 
33. Zeni CP, Tramontina S, Ketzer CR, Pheula GF, Rohde LA.

Methylphenidate combined with aripiprazole in children and adolescents with bipolar disorder and attention-deficit/hyperactivity disorder: a randomized crossover trial. J Child Adolesc Psychopharmacol. 2009;19(5):553-61.

34. Barnett SD, Kramer ML, Casat CD, Connor KM, Davidson JR. Efficacy of olanzapine in social anxiety disorder: a pilot study. J Psychopharmacol. 2002;16(4):365-68

35. Vaishnavi S, Alamy S, Zhang W, Connor KM, Davidson JR. Quetiapine as monotherapy for social anxiety disorder: a placebo-controlled study. Prog Neuropsychopharmacol Biol Psychiatry. 2007;31(7):1464-69.

36. Donahue CB, Kushner MG, Thuras PD, Murphy TG, Van Demark JB, Adson DE. Effect of quetiapine vs. placebo on response to two virtual public speaking exposures in individuals with social phobia. J Anxiety Disord. 2009;23(3):362-68.

37. Depping AM, Komossa K, Kissling W, Leucht S. Second-generation antipsychotics for anxiety disorders. Cochrane Database Syst Rev.

2010;(12):CD008120. Available at: http://www.update-software.com/bcp/ wileypdf/en/cd008120.pdf. Accessed June 29, 2012.

38. Merideth C, Cutler A, Neijber A, et al. Efficacy and tolerability of extended release quetiapine fumarate monotherapy in the treatment of GAD. European Neuropsychopharmacology. 2008;18(Suppl 4):S499-S500.

39. Bandelow B, Chouinard G, Bobes J, et al. Extended-release quetiapine fumarate (quetiapine XR): a once-daily monotherapy effective in generalized anxiety disorder. Data from a randomized, double-blind, placebo- and active-controlled study. Int J Neuropsychopharmacol. 2010;13(3):305-20.

40. Joyce M, Khan A, Eggens I, et al. Efficacy and safety of extended release quetiapine fumarate (quetiapine XR) monotherapy in patients with generalized anxiety disorder (GAD). Poster presented at: 161st Annual Meeting of the American Psychiatric Association; May 3-8, 2008; Washington, DC.

41. Katzman MA, Brawman-Mintzer O, Reyes EB, Olausson B, Liu S, Eriksson H. Extended release quetiapine fumarate (quetiapine XR) monotherapy as maintenance treatment for generalized anxiety disorder: a long-term, randomized, placebo-controlled trial. Int Clin Psychopharmacol. 2011:26(1):11-24

42. Lohoff FW, Etemad B, Mandos LA, Gallop R, Rickels K. Ziprasidone treatment of refractory generalized anxiety disorder: a placebo-controlled, double-blind study. J Clin Psychopharmacol. 2010;30(2):185-89.

43. Simon NM, Connor KM, LeBeau RT, et al. Quetiapine augmentation of paroxetine $\mathrm{CR}$ for the treatment of refractory generalized anxiety disorder: preliminary findings. Psychopharmacology (Berl). 2008;197(4):675-81.

44. Altamura AC, Serati M, Buoli M, Dell'Osso B. Augmentative quetiapine in partial/nonresponders with generalized anxiety disorder: a randomized, placebo-controlled study. Int Clin Psychopharmacol. 2011. 26(4):201-05.
45. Prosser JM, Yard S, Steele A, Cohen LJ, Galynker II . A comparison of low-dose risperidone to paroxetine in the treatment of panic attacks: a randomized, single-blind study. BMC Psychiatry. 2009;9:25. Available at: http:// www.ncbi.nlm.nih.gov/pmc/articles/PMC2696444/pdf/1471-244X-9-25.pdf. Accessed June 29, 2012.

46. Ballard C, Waite J. The effectiveness of atypical antipsychotics for the treatment of aggression and psychosis in Alzheimer's disease. Cochrane Database Syst Rev. 2006;(1):CD003476.

47. Schneider LS, Dagerman K, Insel PS. Efficacy and adverse effects of atypical antipsychotics for dementia: meta-analysis of randomized, placebocontrolled trials. Am J Geriatr Psychiatry. 2006;14(3):191-210.

48. De Deyn PP, Katz IR, Brodaty H, Lyons B, Greenspan A, Burns A. Management of agitation, aggression, and psychosis associated with dementia: a pooled analysis including three randomized, placebo-controlled double-blind trials in nursing home residents treated with risperidone. Clin Neurol Neurosurg. 2005;107(6):497-508.

49. Vigen CL, Mack WJ, Keefe RS, et al. Cognitive effects of atypical antipsychotic medications in patients with Alzheimer's Disease: outcomes from CATIE-AD. Am J Psychiatry. 2011;168(8):831-39. Available at: http:// www.ncbi.nlm.nih.gov/pmc/articles/PMC3310182/pdf/nihms348870.pdf. Accessed June 29, 2012.

50. Yury CA, Fisher JE. Meta-analysis of the effectiveness of atypical antipsychotics for the treatment of behavioural problems in persons with dementia. Psychother Psychosom. 2007;76(4):213-18

51. Micca JL, Hoffmann VP, Lipkovich I, Ahl J, Baker RW, Hardy TA. Retrospective analysis of diabetes risk in elderly patients with dementia in olanzapine clinical trials. Am J Geriatr Psychiatry. 2006;14(1):62-70.

52. Olfson M, Marcus SC, Corey-Lisle P, Tuomari AV, Hines P, L'Italien GJ. Hyperlipidemia following treatment with antipsychotic medications. Am J Psychiatry. 2006;163(10):1821-25.

53. De Deyn PP, Jeste D, Mintzer J. Aripiprazole in dementia of the Alzheimer's type. Poster presented at: 16th Annual Meeting of the American Association for Geriatric Psychiatry; 2003; Honolulu, HI.

54. The Sleep Foundation: Sleep in America Poll-2011. Available at: http:// www.sleepfoundation.org/sites/default/files/sleepinamericapoll/SIAP_2011_ Summary_of_Findings.pdf. Accessed June 29, 2012.

55. Ruelaz Maher A, Maglione M, Bagley S,et al. Efficacy and comparative effectiveness of atypical antipsychotic medications for off-label uses in adults: a systematic review and meta-analysis. JAMA. 2011;306(12):1359-69. Available at: http://jama.jamanetwork.com/pdfaccess.ashx?ResourceID=2476 583\&PDFSource=13. Accessed June 29, 2012. 


\begin{tabular}{|c|c|c|c|c|}
\hline Usage & $\begin{array}{l}\text { Strength of } \\
\text { Evidence }\end{array}$ & 2006 Findings & 2011 Findings & 2011 Conclusions \\
\hline Dementia & High & $\begin{array}{l}\text { A published meta-analysis of } 15 \\
\text { PCTs found small but statistically } \\
\text { significant effects favoring treatment } \\
\text { with risperidone and aripiprazole. } \\
\text { There were effects that favored treat- } \\
\text { ment with olanzapine for the BPRS } \\
\text { and the NPI, but these differences } \\
\text { were not statistically significant. } \\
\text { Three studies of quetiapine were } \\
\text { considered too clinically dissimilar } \\
\text { to pool and results for the indi- } \\
\text { vidual studies showed, with one } \\
\text { exception, trends favoring treatment } \\
\text { with quetiapine that did not reach } \\
\text { conventional levels of statistical sig- } \\
\text { nificance. }\end{array}$ & $\begin{array}{l}\text { Overall-In our meta-analysis of PCTs, aripipra- } \\
\text { zole, olanzapine, and risperidone were superior } \\
\text { to placebo as treatment of behavioral symptoms } \\
\text { as measured by total scores on BEHAVE-D, } \\
\text { BPRS, and NPI. Effect sizes were generally con- } \\
\text { sidered to be "small" in magnitude. } \\
\text { Psychosis-In our meta-analysis risperidone was } \\
\text { superior to placebo, as measured by the psycho- } \\
\text { sis subscales of the BEHAVE-AD, BPRS, and NPI. } \\
\text { Results for aripiprazole did not meet conven- } \\
\text { tional levels of statistical significance. } \\
\text { Agitation-In our meta-analysis, aripiprazole, } \\
\text { olanzapine, and risperidone were superior to pla- } \\
\text { cebo, as measured by the agitation subscales of } \\
\text { the BEHAVE-AD, BPRS, NPI, and CMAI. } \\
3 \text { head-to-head trials compared atypicals; none } \\
\text { were found to be superior. }\end{array}$ & $\begin{array}{l}\text { Aripiprazole, olanzapine, } \\
\text { and risperidone have } \\
\text { efficacy as treatment for } \\
\text { behavioral symptoms of } \\
\text { dementia. }\end{array}$ \\
\hline $\begin{array}{l}\text { Depression- } \\
\text { MDD: augmentation } \\
\text { of SSRI/SNRI }\end{array}$ & $\begin{array}{l}\text { Moderate- } \\
\text { risperidone, } \\
\text { aripiprazole, } \\
\text { quetiapine } \\
\text { Low- } \\
\text { olanzapine, } \\
\text { ziprasidone }\end{array}$ & $\begin{array}{l}3 \text { trials assessed the combination } \\
\text { of olanzapine and fluoxetine; } 1 \\
\text { trial each assessed augmentation } \\
\text { of various SSRIs with risperidone, } \\
\text { ziprasidone, and quetiapine; and } 1 \\
\text { study assessed adding risperidone } \\
\text { vs. olanzapine to SSRI. } \\
\text { The combination of olanzapine } \\
\text { and fluoxetine was no better than } \\
\text { fluoxetine alone in improvement of } \\
\text { depressive symptoms at } 8 \text { weeks, } \\
\text { but } 3 \text { trials reported more rapid } \\
\text { improvement in depressive symp- } \\
\text { toms (at } 2 \text { - } 4 \text { weeks) with combina- } \\
\text { tion therapy using olanzapine or } \\
\text { quetiapine. } \\
1 \text { trial that directly compared aug- } \\
\text { mentation therapy between olan- } \\
\text { zapine and risperidone reported no } \\
\text { differences in outcome. }\end{array}$ & $\begin{array}{l}\text { We conducted a meta-analysis using "response" } \\
\text { to treatment and remission as outcome. Pooling } \\
\text { trials that reported the HAM-D as outcome, the } \\
\text { relative risk of responding for participants tak- } \\
\text { ing quetiapine or risperidone was significantly } \\
\text { higher than for placebo. Olanzapine had only } 2 \\
\text { trials, so pooling was not performed; the trials } \\
\text { reported olanzapine superior to placebo. Other } \\
\text { trials reported MADRS scores; the relative risk of } \\
\text { responding for participants taking aripiprazole } \\
\text { was significantly higher than those taking pla- } \\
\text { cebo. Risperidone and ziprasidone were included } \\
\text { in } 2 \text { and } 1 \text { trial, respectively; these reported the } \\
\text { drug superior to placebo. } \\
1 \text { trial compared ziprasidone at differing levels } \\
\text { augmenting sertraline to sertraline alone. This } \\
\text { trial found a greater improvement in CGI-S and } \\
\text { MADRS scores augmenting with ziprasidone at } \\
160 \text { mg than either augmentation with ziprasi- } \\
\text { done at } 80 \text { mg or sertraline alone. However, there } \\
\text { was no significant difference in HAMD-17, CGI-I } \\
\text { or HAM-A scores. }\end{array}$ & $\begin{array}{l}\text { Aripiprazole, quetiapine, } \\
\text { and risperidone have } \\
\text { efficacy as augmentation } \\
\text { to SSRIs/SNRIs for MDD. } \\
\text { Olanzapine and zipra- } \\
\text { sidone may also have } \\
\text { efficacy. }\end{array}$ \\
\hline $\begin{array}{l}\text { Depression- } \\
\text { MDD: Monotherapy }\end{array}$ & Moderate & $\begin{array}{l}3 \text { olanzapine studies (above) also } \\
\text { assessed its efficacy as monotherapy. } \\
\text { Olanzapine alone was no better than } \\
\text { placebo in improving symptoms at } \\
6 \text { or } 12 \text { weeks. Outcomes were too } \\
\text { heterogeneous to allow pooling. }\end{array}$ & $\begin{array}{l}\text { In our meta-analysis of } 5 \text { PCTs, quetiapine } \\
\text { was superior according to relative risk of both } \\
\text { responding and remitted as measured by } \\
\text { MADRS. }\end{array}$ & $\begin{array}{l}\text { Olanzapine does not } \\
\text { have efficacy as mono- } \\
\text { therapy for MDD. } \\
\text { Quetiapine has efficacy } \\
\text { as monotherapy for } \\
\text { MDD. }\end{array}$ \\
\hline $\begin{array}{l}\text { Obsessive- } \\
\text { compulsive } \\
\text { disorder- } \\
\text { augmentation } \\
\text { of SSRI }\end{array}$ & $\begin{array}{l}\text { Moderate- } \\
\text { risperidone } \\
\text { Low- } \\
\text { olanzapine }\end{array}$ & $\begin{array}{l}12 \text { trials used risperidone, olan- } \\
\text { zapine, or quetiapine as augmenta- } \\
\text { tion therapy in patients who were } \\
\text { resistant to treatment with SSRI. } \\
\text { Nine trials were sufficiently similar } \\
\text { clinically to pool. Atypical antipsy- } \\
\text { chotics had a clinically important } \\
\text { benefit (measured by the Y-BOCS) } \\
\text { when used as augmentation therapy. } \\
\text { Relative risk of "responding" signifi- } \\
\text { cant for augmentation with quetiap- } \\
\text { ine and risperidone. There were too } \\
\text { few studies of olanzapine augmenta- } \\
\text { tion to permit separate pooling of } \\
\text { this drug. }\end{array}$ & $\begin{array}{l}\text { Our updated meta-analysis found risperidone } \\
\text { superior to placebo, as measured by changes in } \\
\text { the Y-BOCS. There were too few studies (2) to } \\
\text { permit separate pooling for olanzapine; both tri- } \\
\text { als reported olanzapine superior to placebo. } \\
1 \text { new head-to-head trial found no difference in } \\
\text { effect between olanzapine and risperidone as } \\
\text { SSRI augmentation. I new head-to-head trial } \\
\text { found quetiapine more effective than ziprasidone } \\
\text { as SSRI augmentation. } \\
1 \text { new trial compared quetiapine to clomipramine } \\
\text { as SSRI augmentation. Quetiapine produced a } \\
\text { significant reduction in Y-BOCS score, while clo- } \\
\text { mipramine did not. }\end{array}$ & $\begin{array}{l}\text { Risperidone has efficacy } \\
\text { in improving OCD symp- } \\
\text { toms when used as an } \\
\text { adjunct to SSRI in treat- } \\
\text { ment refractory patients. } \\
\text { Olanzapine may also } \\
\text { have efficacy. } \\
\text { Quetiapine is more effi- } \\
\text { cacious than ziprasidone } \\
\text { and clomipramine for } \\
\text { this purpose. }\end{array}$ \\
\hline
\end{tabular}




\section{APPENDIX Efficacy of Atypical Antipsychotics for Off-Label Use (continued) $^{2}$}

\begin{tabular}{|c|c|c|c|c|}
\hline Usage & $\begin{array}{l}\text { Strength of } \\
\text { Evidence }\end{array}$ & 2006 Findings & 2011 Findings & 2011 Conclusions \\
\hline $\begin{array}{l}\text { Obsessive- } \\
\text { compulsive } \\
\text { disorder- } \\
\text { augmentation of } \\
\text { citalopram }\end{array}$ & $\begin{array}{l}\text { Low- } \\
\text { quetiapine } \\
\text { Very low- } \\
\text { risperidone }\end{array}$ & $\begin{array}{l}1 \text { trial of risperidone reported } \\
\text { no differences between groups in } \\
\text { achieving a response to therapy, but } \\
\text { patients maintained on risperidone } \\
\text { had a significantly longer period of } \\
\text { time to relapse compared with pla- } \\
\text { cebo (102 days vs. } 85 \text { days). }\end{array}$ & $\begin{array}{l}\text { Two new trials found quetiapine superior to pla- } \\
\text { cebo as augmentation for citalopram, according } \\
\text { to Y-BOCS and CGI-I scores. }\end{array}$ & $\begin{array}{l}\text { Quetiapine and risperi- } \\
\text { done may be efficacious } \\
\text { as augmentation to cita- } \\
\text { lopram in OCD patients. }\end{array}$ \\
\hline $\begin{array}{l}\text { Post-traumatic } \\
\text { stress disorder }\end{array}$ & $\begin{array}{l}\text { Moderate- } \\
\text { risperidone } \\
\text { Olanzapine- } \\
\text { low } \\
\text { Quetiapine- } \\
\text { very low }\end{array}$ & $\begin{array}{l}4 \text { trials of risperidone and } 2 \text { trials of } \\
\text { olanzapine, each of at least } 6 \text { weeks } \\
\text { duration, treated patients with } \\
\text { PTSD. } 3 \text { trials enrolled men with } \\
\text { combat-related PTSD; these showed } \\
\text { a benefit in sleep quality, depres- } \\
\text { sion, anxiety, and overall symptoms } \\
\text { when risperidone or olanzapine was } \\
\text { used to augment therapy with anti- } \\
\text { depressants or other psychotropic } \\
\text { medication. } 3 \text { trials of olanzapine } \\
\text { or risperidone as monotherapy for } \\
\text { abused women with PTSD were } \\
\text { inconclusive regarding efficacy. }\end{array}$ & $\begin{array}{l}3 \text { new trials of risperidone were found, allowing } \\
\text { us to conduct a meta-analysis using the CAPS as } \\
\text { outcome. Risperidone was superior to placebo. } \\
\text { There were too few olanzapine studies (2) to } \\
\text { pool; } 1 \text { reported olanzapine superior to placebo, } \\
\text { while } 1 \text { did not. } \\
\text { A new trial found a 3-fold decline in CAPS scores } \\
\text { in patients treated with quetiapine monotherapy } \\
\text { compared with placebo. Exact scores were not } \\
\text { reported. } \\
\text { We also conducted a meta-analysis by condition; } \\
\text { atypicals were efficacious for combat-related } \\
\text { PTSD but not PTSD in abused women. }\end{array}$ & $\begin{array}{l}\text { Risperidone is efficacious } \\
\text { in reducing combat- } \\
\text { related PTSD symptoms } \\
\text { when used as an adjunct } \\
\text { to primary medication. }\end{array}$ \\
\hline $\begin{array}{l}\text { Personality } \\
\text { disorders- } \\
\text { borderline }\end{array}$ & $\begin{array}{l}\text { Low- } \\
\text { aripiprazole } \\
\text { Very low- } \\
\text { quetiapine, } \\
\text { olanzapine }\end{array}$ & $\begin{array}{l}3 \text { trials provide evidence that olan- } \\
\text { zapine is superior to placebo and } \\
\text { may be superior to fluoxetine. The } \\
\text { benefit of adding olanzapine to dia- } \\
\text { lectical therapy in } 1 \text { trial was small. } \\
\text { Aripiprazole was superior to placebo } \\
\text { in } 1 \text { small trial. }\end{array}$ & $\begin{array}{l}\text { One new trial found aripiprazole superior to } \\
\text { placebo in improving SCL-90, HAM-D, and } \\
\text { HAM-A scores at } 8 \text { months and less self-injury at } \\
18 \text { months. One new trial of ziprasidone found } \\
\text { no significant difference in CGI-BPD, depres- } \\
\text { sive, anxiety, psychotic or impulsive symptoms } \\
\text { compared with placebo at } 12 \text { weeks. } 2 \text { new trials } \\
\text { of olanzapine found no difference from placebo } \\
\text { in any outcomes, while another new trial of olan- } \\
\text { zapine found greater change in ZAN-BPD scores } \\
\text { at } 12 \text { weeks, compared with placebo. } 1 \text { new trial } \\
\text { found quetiapine superior to placebo on BPRS, } \\
\text { PANSS scales. Due to heterogeneity of outcomes, } \\
\text { we could not perform a meta-analysis. }\end{array}$ & $\begin{array}{l}\text { Olanzapine had mixed } \\
\text { results in } 7 \text { trials; } \\
\text { aripiprazole was found } \\
\text { efficacious in } 2 \text { trials; } \\
\text { quetiapine was found } \\
\text { efficacious in } 1 \text { trial; and } \\
\text { ziprasidone was found } \\
\text { not efficacious in } 1 \text { trial. }\end{array}$ \\
\hline $\begin{array}{l}\text { Personality } \\
\text { disorders- } \\
\text { schizotypal }\end{array}$ & Low & $\begin{array}{l}\text { Risperidone was superior to placebo } \\
\text { in one small trial. }\end{array}$ & $\begin{array}{l}\text { One new small trial of risperidone found no dif- } \\
\text { ference from placebo on a cognitive assessment } \\
\text { battery. }\end{array}$ & $\begin{array}{l}\text { Risperidone had mixed } \\
\text { results when treating } \\
\text { schizotypal personality } \\
\text { disorder in } 2 \text { small trials. }\end{array}$ \\
\hline $\begin{array}{l}\text { Tourette's } \\
\text { syndrome }\end{array}$ & Low & $\begin{array}{l}\text { Risperidone was superior to placebo } \\
\text { in } 1 \text { small trial, and it was at least } \\
\text { as effective as pimozide or clonidine } \\
\text { for } 8 \text { to } 12 \text { weeks of therapy in the } \\
3 \text { other trials. } 1 \text { trial of ziprasidone } \\
\text { showed variable efficacy vs. placebo. }\end{array}$ & No additional trials. & $\begin{array}{l}\text { Same as } 2006 \text { : } \\
\text { Risperidone is at least as } \\
\text { efficacious as pimozide } \\
\text { or clonidine for Tourette's } \\
\text { syndrome. }\end{array}$ \\
\hline Anxiety & Moderate & Not covered. & $\begin{array}{l}\text { Three PCTs of quetiapine as monotherapy for } \\
\text { GAD could be pooled; relative risk of responding } \\
\text { on HAM-A favored the quetiapine group. } \\
1 \text { head-to-head trial showed no difference } \\
\text { between risperidone and paroxetine on HAM-A } \\
\text { score improvement. } \\
\text { One trial each found quetiapine equally effective } \\
\text { as paroxetine and escitalopram. }\end{array}$ & $\begin{array}{l}\text { Quetiapine has efficacy } \\
\text { as treatment for GAD. }\end{array}$ \\
\hline $\begin{array}{l}\text { Attention-deficit } \\
\text { hyperactivity } \\
\text { disorder- } \\
\text { no co-occurring } \\
\text { disorders }\end{array}$ & Low & Not covered & $\begin{array}{l}1 \text { trial showed risperidone superior to placebo in } \\
\text { reducing scores on the CAS-P version. }\end{array}$ & $\begin{array}{l}\text { Risperidone may be effi- } \\
\text { cacious in treating chil- } \\
\text { dren with ADHD with } \\
\text { no serious co-occurring } \\
\text { disorders. }\end{array}$ \\
\hline
\end{tabular}


Summary of the Comparative Effectiveness Review on Off-Label Use of Atypical Antipsychotics

\section{APPENDIX Efficacy of Atypical Antipsychotics for Off-Label Use (continued) $^{2}$}

\begin{tabular}{|c|c|c|c|c|}
\hline Usage & $\begin{array}{l}\text { Strength of } \\
\text { Evidence }\end{array}$ & 2006 Findings & 2011 Findings & 2011 Conclusions \\
\hline $\begin{array}{l}\text { Attention-deficit } \\
\text { hyperactivity } \\
\text { disorder- } \\
\text { mentally retarded } \\
\text { children }\end{array}$ & Low & Not covered & $\begin{array}{l}1 \text { trial showed risperidone led to greater reduc- } \\
\text { tion in SNAP-IV scores than methylphenidate. }\end{array}$ & $\begin{array}{l}\text { Risperidone may be } \\
\text { superior to methylphe- } \\
\text { nidate in treating ADHD } \\
\text { symptoms in mentally } \\
\text { retarded children. }\end{array}$ \\
\hline $\begin{array}{l}\text { Attention-deficit } \\
\text { hyperactivity } \\
\text { disorder- } \\
\text { children with } \\
\text { bipolar disorder }\end{array}$ & Low & Not covered & $\begin{array}{l}2 \text { trials of aripiprazole showed no effect on } \\
\text { SNAP-IV scores than placebo. }\end{array}$ & $\begin{array}{l}\text { Aripiprazole is ineffica- } \\
\text { cious in reducing ADHD } \\
\text { symptoms in children } \\
\text { with bipolar disorder. }\end{array}$ \\
\hline Eating disorders & $\begin{array}{l}\text { Moderate- } \\
\text { olanzapine } \\
\text { Low- } \\
\text { quetiapine }\end{array}$ & Not covered & $\begin{array}{l}5 \text { trials of olanzapine were found; } 3 \text { reporting } \\
\text { BMI could be pooled. There was no difference in } \\
\text { change in BMI at either } 1 \text { or } 3 \text { months compared } \\
\text { with placebo. } \\
1 \text { trial of quetiapine reported no statistical differ- } \\
\text { ence from placebo in BMI increase at } 3 \text { months. }\end{array}$ & $\begin{array}{l}\text { Olanzapine and quetiap- } \\
\text { ine have no efficacy in } \\
\text { increasing body mass in } \\
\text { eating disorder patients. }\end{array}$ \\
\hline Insomnia & Very low & Not covered & $\begin{array}{l}\text { l small trial }(\mathrm{N}=13) \text { of quetiapine; sleep out- } \\
\text { comes were not statistically different from pla- } \\
\text { cebo. }\end{array}$ & $\begin{array}{l}\text { Quetiapine may be inef- } \\
\text { ficacious in treating } \\
\text { insomnia. }\end{array}$ \\
\hline $\begin{array}{l}\text { Substance abuse- } \\
\text { alcohol }\end{array}$ & $\begin{array}{l}\text { Moderate- } \\
\text { aripiprazole } \\
\text { Low- } \\
\text { quetiapine }\end{array}$ & Not covered & $\begin{array}{l}2 \text { trials of aripiprazole and } 1 \text { of quetiapine } \\
\text { reported percentage of patients completely absti- } \\
\text { nent during follow-up. In our pooled analysis, } \\
\text { the effect vs. placebo was insignificant. }\end{array}$ & $\begin{array}{l}\text { Aripiprazole is ineffica- } \\
\text { cious in treating alcohol } \\
\text { abuse/dependence. } \\
\text { Quetiapine may also be } \\
\text { inefficacious. }\end{array}$ \\
\hline $\begin{array}{l}\text { Substance abuse- } \\
\text { cocaine }\end{array}$ & Low & Not covered & $\begin{array}{l}2 \text { trials of olanzapine and } 1 \text { of risperidone } \\
\text { reported there was no difference in efficacy vs. } \\
\text { placebo as measured by the ASI. }\end{array}$ & $\begin{array}{l}\text { Olanzapine is ineffica- } \\
\text { cious in treating cocaine } \\
\text { abuse/dependence. } \\
\text { Risperidone may also be } \\
\text { inefficacious. }\end{array}$ \\
\hline $\begin{array}{l}\text { Substance abuse- } \\
\text { methamphetamine }\end{array}$ & Low & Not covered & $\begin{array}{l}1 \text { trial found aripiprazole inefficacious in } \\
\text { reducing use of intravenous amphetamine, as } \\
\text { measured by urinalysis. Another trial found } \\
\text { aripiprazole inefficacious in reducing craving for } \\
\text { methamphetamine. }\end{array}$ & $\begin{array}{l}\text { Aripiprazole is ineffica- } \\
\text { cious in treating meth- } \\
\text { amphetamine abuse/ } \\
\text { dependence. }\end{array}$ \\
\hline $\begin{array}{l}\text { Substance abuse- } \\
\text { methadone clients }\end{array}$ & Low & Not covered & $\begin{array}{l}1 \text { trial of methadone clients found no difference } \\
\text { between risperidone and placebo in reduction of } \\
\text { cocaine or heroin use. }\end{array}$ & $\begin{array}{l}\text { Risperidone is an ineffi- } \\
\text { cacious adjunct to metha- } \\
\text { done maintenance. }\end{array}$ \\
\hline
\end{tabular}

Source: Table B in: Maglione M, Ruelaz Maher A, Hu J, et al. Off-label use of atypical antipsychotics: an update. AHRQ comparative effectiveness review no. 43.

September 2011. ${ }^{1}$

a Some of the text included in this table is identical to the source text.

$A D H D=$ attention-deficit hyperactivity disorder; ASI = Addiction Severity Index; BEHAVE-AD = Behavioral Pathology in Alzheimer's Disease Rating Scale; BMI = body mass index; BPRS = Brief Psychiatric Rating Scale; CAPS =Clinician Administered PTSD Scale; CAS-P=Children's Aggression Scale-Parent version; CGI-BPD=clinical global impression scale for borderline personality disorder; CGI-I=clinical global impression improvement; CGI-S=clinical global impression-severity; CMAI = CohenMansfield Agitation Inventory; GAD = generalized anxiety disorder; HAM-A = Hamilton Anxiety Scale; HAM-D = Hamilton Depression Scale; MADRS=MontgomeryAsberg Depression Rating Scale; $M D D=$ major depressive disorder; $m g=$ milligram; NPI = Neuropsychiatric Inventory; OCD =obsessive-compulsive disorder; PANSS = Positive and Negative Syndrome Scale; PCT = placebo-controlled trial; PTSD = post-traumatic stress disorder; SCL-90=Symptom Checklist 90; SNAP$I V=S w a n s o n, N o l a n$, and Pelham teacher \& parent rating scale; SNRI=serotonin norephinephrine reuptake inhibitor; SSRI=selective serotonin reuptake inhibitor; Y-BOCS = Yale-Brown Obsessive Compulsive Scale; ZAN-BPD = Zanarini rating scale for borderline personality disorder. 


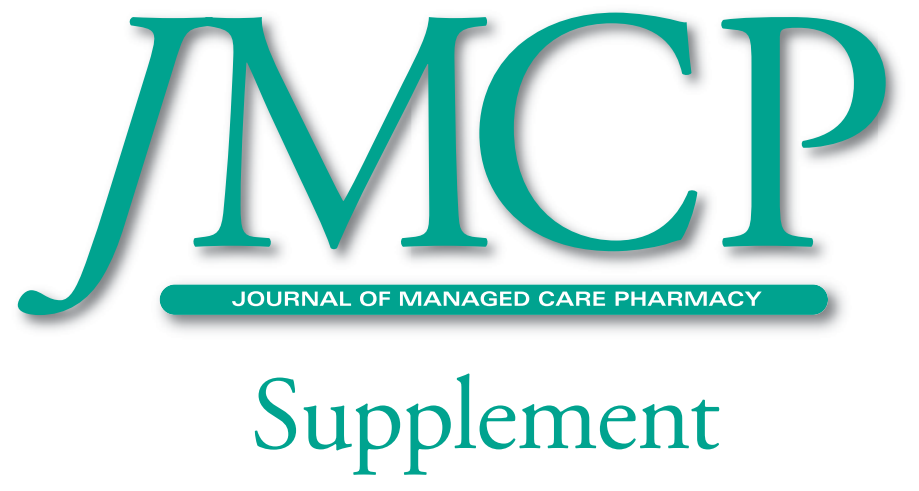

